\title{
El reto de los dispositivos móviles en las aulas universitarias: una respuesta actual al trabajo autónomo y a la evaluación virtual
}

\author{
Antonio Carreras Casanovas \\ Profesor Ad Honorem del Departamento de Derecho Público, área de Constitucional, de la \\ Facultad de Ciencias Jurídicas de la Universidad Rovira i Virgili (Tarragona, España) \\ antonio.carreras@urv.cat | https://orcid.org/0000-0003-0710-9132
}

\begin{abstract}
Este trabajo ha obtenido un Accésit del Premio Estudios Financieros 2020 en la modalidad de Educación y Nuevas Tecnologías.

El jurado ha estado compuesto por: don Manuel Area Moreira, doña Eva María Bailén Fernández, don Julio Cabero Almenara, doña Ana García-Valcárcel Muñoz-Repiso, don Pedro José González Felipe y don Alfonso Gutiérrez Martín.
\end{abstract}

Los trabajos se presentan con seudónimo y la selección se efectúa garantizando el anonimato de los autores.

\section{Extracto}

Proyecto metodológico que pretende convertir los dispositivos móviles en un recurso educativo. Se ha implantado durante dos años en un colectivo de 421 estudiantes de las facultades de Ciencias Jurídicas y Letras de la Universidad Rovira i Virgili de Tarragona entre los que el uso de los teléfonos móviles en las aulas ha sido constante. Para ello se han replanteado las competencias y la metodología con la finalidad de adaptarlas a los móviles. El proyecto se ha basado en la experiencia aplicada de las apps comerciales, en el análisis de los resultados obtenidos y en el diseño, desarrollo e implementación de una nueva app. Para su implementación se ha creado una beca-proyecto de carácter social, destinada a la igualdad de género para colectivos de estudiantes (mujeres) vulnerables por razón de su religión o etnia. Los resultados obtenidos han sido mayor motivación, participación, dinamismo, reinvención de la metodología y posibilitar la educación tecnológica. En conclusión, se ha dado una respuesta al reto de los dispositivos móviles en las aulas universitarias.

Palabras clave: m-learning; app; dispositivos móviles; aula; motivación.

Fecha de entrada: 01-06-2020 / Fecha de aceptación: 18-09-2020

Cómo citar: Carreras Casanovas, A. (2021). El reto de los dispositivos móviles en las aulas universitarias: una respuesta actual al trabajo autónomo y a la evaluación virtual. Tecnología, Ciencia y Educación, 19, 7-52. https://doi.org/10.51302/tce.2021.624 


\title{
The challenge of mobile devices in university classrooms: a current response to autonomous work and virtual assessment
}

\author{
Antonio Carreras Casanovas
}

\section{Abstract}

Methodological project that aims to turn up mobile devices into an educational resource. It was implemented in a group of 421 students from the Faculties of Law and Social Sciences of Universiti Rovira i Virgili of Tarragona for two years. In this group, the use of mobile phones was used in classrooms. We readapted the traditional competencies and methodology to apply them to mobiles. The project was based on the practical experience with commercial apps, the analysis of the obtained results and the design, development and implementation of a new app. For its implementation, a Social Project Grant was created, aimed at gender equality for groups of students (women) vulnerable due to their religion or ethnicity. The results obtained were: greater motivation, participation, dynamism, reinvention of the methodology and the possibility of technological education. In conclusion, there was a response to the challenge of mobile devices in university classrooms.

Keywords: m-learning; app; mobile devices; classroom; motivation.

Citation: Carreras Casanovas, A. (2021). The challenge of mobile devices in university classrooms: a current response to autonomous work and virtual assessment. Tecnología, Ciencia y Educación, 19, 7-52. https://doi.org/10.51302/tce.2021.624 


\section{Sumario}

1. Motivación y justificación

2. Comprobación y efectividad del uso de los dispositivos móviles en el aula

2.1. Replanteamiento de la metodología docente y plan de trabajo

2.2. Competencias digitales marcadas

2.2.1. Competencias digitales específicas (objetivos de contenidos competenciales)

2.2.2. Competencias digitales transversales (objetivos de aprendizaje)

2.2.3. Competencias digitales nucleares (objetivos de formación personal)

2.3. Planificación del trabajo con los dispositivos móviles

2.3.1. Clases magistrales

2.3.2. Clases prácticas

2.3.3. Registro de la asistencia a diferentes eventos a través del móvil

2.3.4. Componente lúdico-musical de la app

2.4. Parametrización de datos

2.4.1. Registro de asistencia

2.4.2. Registro de resultados del test fuera del aula

2.4.3. Registro de los resultados de los test quincenales

2.4.4. Tutorías inteligentes

2.5. Ventajas e inconvenientes del uso del móvil en el aula

3. Diseño de una app personalizada y transversal

3.1. Apps comerciales para la docencia universitaria

3.2. Ventajas e inconvenientes de una app de nueva creación

3.3. Pautas para la creación de la nueva app

3.4. Diseño y parametrización de la app de nueva creación

\subsubsection{Funciones y contenidos}

4. Planificación económica, desarrollo e implantación

4.1. Planificación y cuantificación

4.2. Cuantificar el coste

4.3. Micromecenazgo

4.4. Creación de una beca-proyecto

4.5. Colaboraciones 
4.5.1. Implicación de departamentos y facultades

4.5.2. Equipo de trabajo

4.6. La nueva app «Gaudeamus Virtual Education»

5. Criterios institucionales en los que se puede enmarcar este método

5.1. Alineación con los planes estratégicos de la universidad

5.1.1. Plan de igualdad

5.1.2. Compromiso con los valores

5.1.3. Capacidad de mejora e innovación en el ámbito disciplinario

5.1.4. Segundo Plan Estratégico de Investigación e Innovación

6. Resultados obtenidos

6.1. Eficacia metodológica

6.2. Aceptabilidad y satisfacción por parte del alumnado

6.3. Impacto en la docencia

6.4. Visibilidad del método

7. Conclusiones

Referencias bibliográficas 


\section{Motivación y justificación}

La presencia de los dispositivos móviles en las aulas es un hecho incuestionable. Los móviles han venido para quedarse. Seguro que no los podremos vencer; por lo tanto, debemos ser imaginativos para reconvertirlos en un aliado de la docencia. Es responsabilidad de los docentes saber transformar y aprovechar con imaginación esta potente herramienta que la tecnología pone al alcance. Este es un reto que tiene la universidad y al que hay que dar una respuesta actual.

La presencia de las nuevas tecnologías en el mundo universitario plantea dos opciones: seguir con el método de enseñanza tradicional o incorporar métodos actuales adecuados. La necesidad de acoplamiento de estos dos métodos a los nuevos tiempos es esencial para el éxito de la docencia futura (Reyero, 2019). Y más aún con las circunstancias que hemos vivido por el impacto de la COVID-19. Las nuevas tecnologías cuestionan las clases magistrales clásicas y nos dan la oportunidad de incorporar las ventajas que ellas nos ofrecen. Es bien sabido que los estudiantes se prodigan en el uso de la telefonía móvil y que a menudo esto se convierte en un adversario al

La presencia de las nuevas
tecnologías en el mundo
universitario plantea dos opciones:
seguir con el método de enseñanza
tradicional o incorporar métodos
actuales adecuados. La necesidad
de acoplamiento de estos dos
métodos a los nuevos tiempos
es esencial para el éxito de la
docencia futura. Y más aún con las
circunstancias que hemos vivido
por el impacto de la COVID-19
que el docente debe enfrentarse para conseguir mantener su atención en las clases. ¿No sería mejor poder convertir esta tecnología en un recurso para el aprendizaje, en una herramienta de apoyo para las clases, en un elemento que ayude al profesorado a captar la atención, a hacer participar a los estudiantes en el aula con más motivación e, incluso, a utilizarlo en procesos evaluativos no presenciales? Si esto se consigue, el salto cualitativo en la docencia es remarcable y convertiremos el dispositivo móvil en un aliado y no en un estorbo.

Este uso de los smartphones, entendido como el conjunto de metodologías para enseñar y aprender a través de los dispositivos móviles, se conoce como $m$-learning o aprendizaje electrónico móvil (teléfonos móviles, PDA [personal digital assistant], tabletas, PocketPC, iPod y otros dispositivos que tengan una conectividad inalámbrica) (Santiago et al., 2015) ${ }^{1}$

\footnotetext{
1 https://www.inspiratics.org/recursos-educativos/el-movil-en-el-aula-ideas-ventajas-retos-y-posibilidades
} 
y, poco a poco, se ha implantado en el mundo de la enseñanza no superior, en el que las universidades no pueden quedar al margen.

Con el ánimo de promover la innovación y la mejora de la docencia en la Facultad de Ciencias Jurídicas de la Universidad Rovira i Virgili de Tarragona a través del perfeccionamiento de los procesos de aprendizaje y de los sistemas metodológicos tradicionales, se ha incorporado el uso de los dispositivos móviles a las materias que hemos impartido en los estudios de grado de la Facultad de Ciencias Jurídicas y de la Facultad de Letras (Periodismo, Comunicación Audiovisual y Publicidad y Relaciones Públicas).

El proyecto que presentamos y que hemos desarrollado a modo de prueba piloto ha seguido la siguiente metodología científica de trabajo: observación, investigación e innovación. Es decir, uso intensivo de los dispositivos móviles en las clases, comprobación de su efectividad como recurso educativo, diseño de una app personalizada y transversal para facultades/universidades y planificación económica e implantación.

Para implantar su uso y comprobar su efectividad en el aula, hemos utilizado diferentes apps (aplicaciones para teléfonos móviles inteligentes, tabletas y otros dispositivos móviles) existentes en el mercado (Kahoot!, Nearpod, Mentimeter, Socrative, etc.). Estas apps nos han permitido introducir nuevos métodos a la hora de impartir la materia y valorar su efectividad.

La experiencia alcanzada con esta investigación, desde nuestro punto de vista exitosa, ha permitido diseñar el desarrollo de una app propia para la Universidad Rovira i Virgili, que puede servir de pauta para otras universidades, con resultados que podrían ser relevantes, dadas sus múltiples funciones y su transversalidad a otras facultades, convirtiéndose en un proyecto pionero para nuestra universidad. Para su creación e implementación se

La experiencia alcanzada, desde nuestro punto de vista exitosa, ha permitido diseñar el desarrollo de una app propia para la Universidad Rovira i Virgili, que puede servir de pauta para otras universidades han buscado fondos de financiación y se ha contado con la colaboración de la Escuela Técnica Superior de Ingeniería (ETSI), a la vez que se ha creado una beca-proyecto de carácter social.

\section{Comprobación y efectividad del uso de los dispositivos mó- viles en el aula}

\subsection{Replanteamiento de la metodología docente y plan de tra- bajo}

Para introducir el uso de los dispositivos móviles en la docencia se tuvo que replantear el sistema tradicional de las clases magistrales y de las clases de prácticas con la finalidad de 
adaptarlas a esa nueva tecnología. Primero se fijaron una serie de competencias digitales u objetivos, después se replanteó la metodología docente para adaptarla a las nuevas competencias y, finalmente, se estructuró un plan de trabajo adaptado al uso de los dispositivos móviles. El proyecto se puso en marcha durante los cursos académicos 2018-2019 y 2019-2020 en la materia de Derecho Constitucional de dos grados de las facultades de Ciencias Jurídicas y de Letras de la Universidad Rovira i Virgili:

\section{El proyecto de investigación se puso en marcha durante los cursos académicos 2018-2019 y 2019-2020 en la materia de Derecho Constitucional de dos grados de las facultades de Ciencias Jurídicas y de Letras de la Universidad Rovira i Virgili}

- Curso 2018-2019 (Facultad de Ciencias Jurídicas):

- Grado de Derecho (líneas de mañana y tarde).

- Asignatura: Constitución y Sistema de Fuentes ( 9 créditos ECTS [European Credit Transfer System]). Primer curso (1. $\left.{ }^{\circ} \mathrm{Q}\right)$.

- Cursos 2018-2019 y 2019-2020 (Facultad de Letras):

- Grados de Periodismo, Comunicación Audiovisual y Publicidad y Relaciones Públicas (líneas de mañana y tarde).

- Asignatura: Ordenamiento Jurídico y Sistema Político (9 créditos ECTS). Primer curso (1. $\left.{ }^{\circ} \mathrm{Q}\right)$.

El conjunto de estudiantes a los que se les ha aplicado esta metodología docente ha sido de 421, desglosados de la siguiente manera (véase cuadro 1):

Cuadro 1. Número de estudiantes a los que se les ha aplicado el método

\begin{tabular}{|c|c|c|c|c|c|}
\hline \multicolumn{6}{|c|}{ Grados } \\
\hline \multirow[t]{2}{*}{ Cursos } & \multicolumn{2}{|c|}{ Derecho } & \multicolumn{2}{|c|}{$\begin{array}{l}\text { Periodismo/Comunicación } \\
\text { Audiovisual/Publicidad y } \\
\text { Relaciones Públicas }\end{array}$} & \multirow[t]{2}{*}{ Tota } \\
\hline & Mañana & Tarde & Mañana & Tarde & \\
\hline 2018-2019 & 94 & 64 & 72 & 55 & 285 \\
\hline 2019-2020 & & & 66 & 70 & 136 \\
\hline Total & 94 & 64 & 138 & 125 & 421 \\
\hline
\end{tabular}




\subsection{Competencias digitales marcadas}

La utilización sistemática del uso de los dispositivos móviles en el aula ha requerido una adaptabilidad de las competencias a estas nuevas tecnologías y una reinvención de los planteamientos competenciales (véase figura 1).

\subsubsection{Competencias digitales específicas (objetivos de contenidos com- petenciales)}

\section{A) Asimilación de los contenidos y evaluación personalizada}

A través del uso de los dispositivos móviles se ha buscado la forma de mejorar la asimilación de contenidos de la materia impartida, así como optimizar los procesos evaluativos presenciales y virtuales con un seguimiento más individualizado de cada estudiante con el fin de mejorar los resultados finales. El objetivo es que los dispositivos móviles se conviertan para el conjunto de los estudiantes en una plataforma de participación y de trabajo en las tareas del curso, a la vez que en una fuente de información.
Uno de los objetivos es que los dispositivos móviles se conviertan para el conjunto de los estudiantes en una plataforma de participación y de trabajo en las tareas del curso, a la vez que en una fuente de información

\section{B) Dinamismo y participación masiva del alumnado}

A menudo, la participación oral de los estudiantes en las clases es minoritaria. Muchos de ellos se retraen a la hora de expresar su opinión o preguntar en público. El uso de los dispositivos móviles permite una participación masiva, la interacción de todo el alumnado y ver su grado de comprensión, lo que con el método tradicional no se alcanzaba. Por tanto, el objetivo es hacer más participativas y dinámicas las clases, sin descuidar la participación oral.

\author{
El uso de los dispositivos \\ móviles permite una participación \\ masiva, la interacción de todo \\ el alumnado y ver cuál es \\ su grado de comprensión, lo \\ que con el método tradicional \\ no se alcanzaba en absoluto
}

\subsubsection{Competencias digitales transversales (objetivos de aprendizaje)}

\section{A) Convertir el móvil en una nueva herramienta para la docencia}

Los dispositivos móviles ofrecen una potencialidad tecnológica que el profesorado no puede desaprovechar: respuesta inmediata y personalizada de cada estudiante ante las pre- 
guntas, opiniones y sondeos planteados a la clase, correcciones instantáneas de exámenes (presenciales y virtuales), confección automática de bases de datos y tutorías inteligentes, etc. Estas son algunas de las ventajas que ofrecen las nuevas tecnologías. El objetivo es transformar los dispositivos móviles en una potente herramienta para la docencia y minimizar su uso particular durante la clase.

\section{Transformar los dispositivos móviles en una potente herramienta para la docencia y minimizar su uso particular durante la clase es otro de los objetivos de este estudio}

\section{B) Motivar al estudiante a través de las nuevas tecnologías}

Dada la tendencia natural del alumnado al uso de los móviles en sus vidas, la utilización de estos dispositivos como una herramienta de docencia supone entrar en su mundo virtual, donde el móvil es un elemento de vinculación social, de relevancia de su personalidad, donde se dan a conocer en las redes sociales y donde encuentran entretenimiento y creatividad. Este mundo lúdico/social tiene buen predicamento entre los jóvenes y, por tanto, convertirlo en una herramienta docente es acercar el aprendizaje a su universo, en el que están a gusto. El componente altamente teórico de muchas materias se encuentra, con frecuencia, alejado de la realidad que vive el alumnado. Si lo acercamos a su mundo a través de sus dispositivos móviles y con las herramientas que mejor conocen, la materia se vuelve amigable e interesante y, de este modo, el estudiante no se cierra, sino que se abre con motivación (Reyero, 2019; Yániz, 2006).

\section{C) Razonamiento crítico}

Gestionar conocimientos a través de los móviles, convirtiéndolos en una fuente de información que les conduzca a entender mejor la materia, y que sean los estudiantes, con apoyo del profesorado, quienes construyan sus propias competencias con ayuda de los móviles (Bain, 2007).

\section{D) Educación tecnológica}

Hacer un buen uso del móvil en la universidad. También luchar contra el llamado phubbing, o la acción de prestar más atención al móvil que a las personas, y aprender a hacer un buen empleo de la tecnología móvil.

\subsubsection{Competencias digitales nucleares (objetivos de formación personal)}

\section{A) Compromiso ético}

La participación de todos los estudiantes en la toma de decisiones (casos simulados de comportamiento social y democrático, etc.) a través de votaciones anónimas con los móviles 
pone de manifiesto su grado de compromiso ético, de responsabilidad y de honradez. Este componente permite ejemplificar la necesidad de mantener estos valores en la formación de los estudiantes como personas y miembros de una sociedad democrática. La importancia de los valores (responsabilidad, honradez, honestidad, tolerancia, entre otros) se ha marcado como objetivo prioritario.

\section{La importancia de los valores (responsabilidad, honradez, honestidad, tolerancia, entre otros) se ha marcado como objetivo prioritario de este trabajo de investigación educativa}

\section{B) Ejercitar la responsabilidad democrática}

La materia de Derecho Constitucional acerca al estudiante a los mecanismos democráticos de participación. Para ejercitar este derecho fundamental se han preparado clases prácticas donde la decisión final depende del voto de toda la clase, con votaciones telemáticas. El objetivo es convertir el móvil en una papeleta de voto para que los estudiantes puedan manifestar su compromiso democrático con una elección responsable y madura.

\section{Otro de los objetivos es convertir el teléfono móvil en una papeleta de voto para que los estudiantes puedan manifestar su compromiso democrático con una elección responsable y plenamente madura}

Figura 1. Competencias digitales adaptadas a los móviles

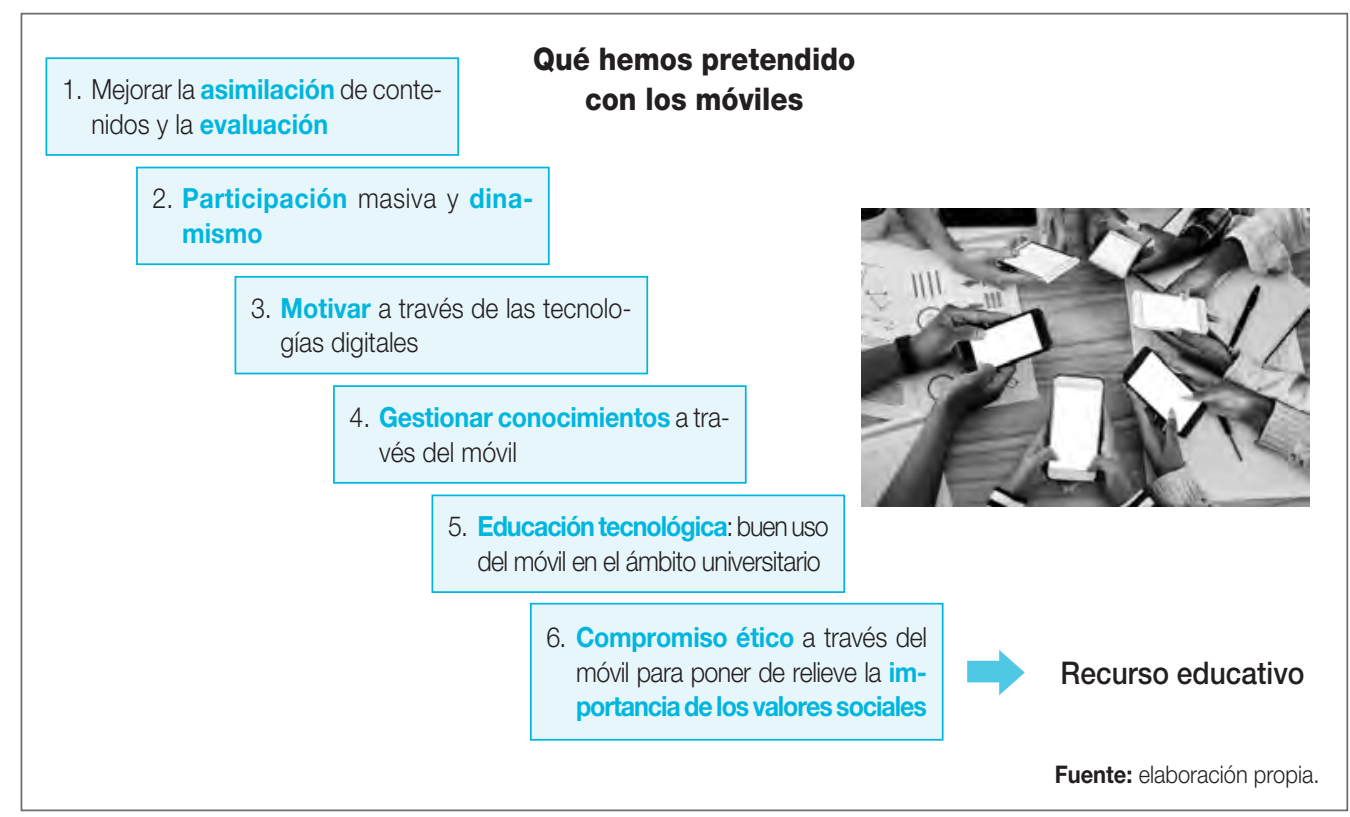




\subsection{Planificación del trabajo con los dispositivos móviles}

Para conseguir estos objetivos se ha realizado el siguiente plan de trabajo, pensado para que los dispositivos móviles tengan un papel notable tanto en la clase como fuera del aula (véase figura 2).

\subsubsection{Clases magistrales}

\section{A) Trabajos fuera del aula (homework) a través de la app del móvil}

En las clases magistrales se utiliza el método de aprendizaje conocido como «aula invertida» (flipped classroom o flip teaching) (Berenguer-Albaladejo, 2016; García-Barrera, 2013) que permite introducir las posibilidades que da el móvil para captar el grado de asimilación de la materia. Con la clase inversa el estudiante aprende nuevos contenidos a través de las tecnologías de la información y la comunicación (TIC) fuera del aula. Para ello hemos creado una página web de cada asignatura en la que el alumnado encuentra toda la información necesaria para entrar en contacto con la materia antes de ser explicada por el docente en clase (https://sites.google.com/site/constiaccperiodisme/). Previamente a la clase magistral, el estudiante habrá tenido que contestar a través de la app de su móvil un test con preguntas de comprensión. Una vez cerrado el periodo hábil para las contestaciones, las respuestas le llegan al docente vía online a través de un fichero Excel que genera la propia app. En este archivo quedan registrados el orden cronológico de respuesta, los aciertos y errores de cada estudiante, así como los porcentajes globales. Esto permite al profesorado saber el grado de asimilación de los contenidos previos a sus explicaciones; es decir, los estudiantes más diligentes -que han contestado antes-, los errores $\mathrm{y}$, por tanto, los contenidos que no se han asimilado. El conocimiento previo de la materia incentiva al alumnado y propicia los debates en clase. En consecuencia, el docente ya sabe, previamente antes de la clase, lo que ha quedado claro y lo que no, incidiendo en ello a través del fomento de las preguntas y del debate en las clases magistrales. Los trabajos fuera del aula a través
de la app del móvil permiten al
profesorado saber el grado de
asimilación de los contenidos
previos a sus explicaciones

\section{B) Feedback con el móvil}

En las presentaciones de las clases magistrales (PowersPoints) se intercalan, aproximadamente cada 30 minutos, las mismas preguntas tipo test que se plantearon en la clase inversa fuera del aula y algunas otras. Los estudiantes vuelven a contestar las preguntas con sus dispositivos móviles. Un gráfico en la pantalla del aula muestra los porcentajes de aciertos y de errores y es ahora cuando el docente aclara e incide en las respuestas 
incorrectas. Esto permite la participación masiva de toda la clase, lo que crea competitividad entre los propios estudiantes, muestra el grado de asimilación de la materia y relaja el aprendizaje de las explicaciones largas, además de reforzar los contenidos poco asimilados y avanzar progresivamente en la comprensión de la materia.
El feedback con el dispositivo móvil permite reforzar los contenidos poco asimilados y avanzar progresivamente en la comprensión de la materia

\section{C) Búsqueda de información con el móvil}

Frecuentemente, las explicaciones de la materia requieren aportación de datos, información legal, contextual, estadística, etc. Esta búsqueda de información se hace a través de los móviles de los estudiantes, a los que se les pide que participen con sus dispositivos. Se intenta que sea competitivo para que buena parte del alumnado se implique en la búsqueda. Utilizado en su justa medida, este recurso da credibilidad e ilustra los contenidos expuestos. También acerca la materia a un mundo tecnológico en el que el estudiantado suelen moverse muy bien. Los estudiantes participan en la búsqueda de contenidos a través de sus dispositivos (iPhones, iPads, ordenadores, etc.), convirtiéndose en cómplices de la investigación y de la información, y reforzando la credibilidad.
Los estudiantes participan en la búsqueda de contenidos a través de sus dispositivos (iPhones, iPads, ordenadores, etc.), convirtiéndose en cómplices de la investigación y de la información, y reforzando la credibilidad

\section{D) Test quincenal con el móvil}

Cada dos semanas se preparará un test con diez preguntas de elección múltiple sobre los contenidos impartidos en las clases anteriores con el fin de estimular al alumnado para que repase la materia dada y crear así hábitos de estudio diarios. Estos test evaluables son preparados por el profesorado a través de la app. Un código alfanumérico permite la entrada de los estudiantes en la app durante la clase. Allí introducen sus datos personales identificativos. A continuación, aparecen en la pantalla del aula las preguntas con sus opciones de respuesta. No así en sus dispositivos, donde solo aparecen las posibles respuestas ( $a, b, c$ y d). El tiempo de respuesta de cada pregunta se puede programar a voluntad del docente. Para evitar la copia, las respuestas que aparecen en los dispositivos de cada estudiante pueden ser aleatorias, lo que evita visualizar el móvil del compañero y, por ende, la respuesta. Al final del test, en la pantalla del aula salen las contestaciones acertadas, el porcentaje de respuestas correctas y el nombre de los estudiantes mejor calificados, lo que da un componente de competitividad al test. A continuación, la app genera un fichero Excel con el nombre de cada estudiante y las respuestas correctas y erróneas individualizadas. Esta aplicación envía el archivo al docente de forma online, con las calificaciones 
inmediatas, lo que facilita la corrección enormemente y sin posibilidades de errores de cálculo, y, a su vez, envía las correspondientes calificaciones al alumnado. Esta prueba evaluativa tiene también una versión que puede ser realizada de forma virtual si se dan las circunstancias.

\section{Un test quincenal con el móvil estimula al alumnado a repasar la materia impartida y a crear hábitos de estudio diarios}

\section{E) Registro de las clases magistrales con audio a través del móvil}

Con el fin de dar un mayor apoyo a los estudiantes fuera del aula, el docente utiliza su propio dispositivo móvil con la app de «Notas de voz» para registrar en audio las clases magistrales. Una vez realizada una pequeña posproducción y el etiquetado, las cuelga en Moodle como archivos de voz. El estudiante puede reproducir la clase según sus necesidades tantas veces como quiera. Este método sencillo mejora el aprendizaje y es altamente valorado por todo el alumnado.

\section{Cada estudiante puede reproducir la clase según sus necesidades tantas veces como quiera}

\subsubsection{Clases prácticas}

Es en este bloque de clases prácticas donde la utilización de los móviles permite una mayor flexibilidad y un amplio abanico de posibilidades en función del grado de adaptación imaginativa que ponga el docente. Siguiendo el método habitual de las prácticas que se venían realizando en estas asignaturas, se ha introducido esta nueva herramienta que ha permitido una mayor participación y más posibilidades.

\section{A) Liga de debates}

Consiste en un foro de discusión pensado para poner de manifiesto la importancia de la materia impartida (en este caso, el Derecho Constitucional) en la realidad cotidiana que vive el alumnado. La materia del debate versa sobre política, sociedad, economía, etc.; temas recurrentes que aparecen en los medios de comunicación y que interesan al alumnado (los políticos, la corrupción, la inmigración, la igualdad de género, la monarquía versus república, etc.).

- Búsqueda de datos argumentales para refutar al contrincante a través de los móviles. La dinámica de la liga consiste en dividir la clase en grupos de trabajo, tantos como días de debate. En cada debate intervendrán dos grupos paritarios, que defenderán posturas contradictorias, sin que sepan previamente qué postura les tocará defender, lo que les obliga a preparar las dos posturas. Así se trabaja el 
razonamiento y la defensa de postulados contrarios a los propios pensamientos, a la vez que se preserva el anonimato del pensamiento individual. Cada grupo expone sus argumentos, los cuales son rebatidos, por turnos, por el otro grupo con datos extraídos de sus dispositivos móviles (los componentes del grupo se afanan en buscar estos datos para dar argumentos contundentes al orador que defiende la postura y así poder refutar los argumentos del contrincante). El uso de los móviles y de las webs es constante en el transcurso de todo el debate. Recordemos que la implicación potencia el aprendizaje.

- Votación con los móviles. Al finalizar el debate, el docente da acceso a la app. Un código pin permite que cada estudiante, de forma anónima, vote al grupo que considere ganador del debate. Al terminar la votación aparecerá en la pantalla del aula el número de votos otorgados a cada grupo y, en consecuencia, el grupo ganador de aquella fase de la liga de debates, y así sucesivamente hasta llegar a la final, donde saldrá elegido el equipo ganador de la liga. Esto conlleva una calificación progresiva para los equipos ganadores que han sido elegidos por sus propios compañeros. El equipo ganador obtiene una calificación máxima de 2 puntos sobre la nota final. En este aspecto es donde interviene el compromiso ético de responsabilidad y honradez para tomar una decisión personal y anónima que no esté influenciada por el grado de amistad o enemistad hacia uno de los equipos, sino por la calidad de sus planteamientos y exposiciones.

\section{B) Simulaciones electorales con los móviles}

Otra práctica consiste en que dos grupos se constituyen en partido político simulado, elaboran los correspondientes estatutos, hacen la inscripción en el Registro de Partidos Políticos, preparan la campaña electoral que es expuesta a la clase con mítines, spots publicitarios, etc., para acabar con un discurso de investidura de cada candidato con el programa de gobierno que pretende la simulada presidencia del Gobierno. Tras las correspondientes sesiones, la clase se convierte virtualmente en el hemiciclo del Congreso y el alumnado elige al candidato del partido ganador, con una votación telemática online a través de sus dispositivos móviles. El resultado aparece en la pantalla del aula con el número de votos a favor, en contra y en blanco. Esto permite ensayar sistemas de votación telemática con listas cerradas y bloqueadas, y, en sesiones posteriores, con listas abiertas a través de papeletas simuladas que aparecen en sus móviles.

\subsubsection{Registro de la asistencia a diferentes eventos a través del móvil}

En los cursos anteriores se llevaba un registro de asistencia mediante la recogida de firmas en papel y la consiguiente tarea para el profesorado de anotar la asistencia en un registro informático. Con la incorporación de la app del móvil, el registro de asistencia a las clases es lúdico para el alumnado, online y rápido para el docente. 
Al llegar a clase, el docente proyecta en la pantalla del aula el código pin de la sesión. Cada estudiante entra con su móvil en la app, introduce el código y, a continuación, sus datos. El docente activa la pregunta de la asistencia a la que cada estudiante debe contestar. Al finalizar se genera un fichero Excel con la relación de todos los estudiantes asistentes. El archivo se envía automáticamente al docente para que pueda ser tratado en su base de datos, lo que le permite sacar porcentajes de asistencia diarios y hacer un seguimiento individualizado de la asistencia de cada estudiante durante el curso, si lo cree conveniente.

\subsubsection{Componente lúdico-musical de la app}

La app lleva incorporado un sistema de audio que permite mantener una música rítmica al comenzar y al finalizar cada actividad. Está pensado para ayudar psicológicamente a crear un clima lúdico en la clase, ya que el estudiante se familiariza con el audio y esto contribuye a la segregación de endorfinas positivas, con lo que afronta relajado la explicación de la materia.

Figura 2. Innovación metodológica con el móvil

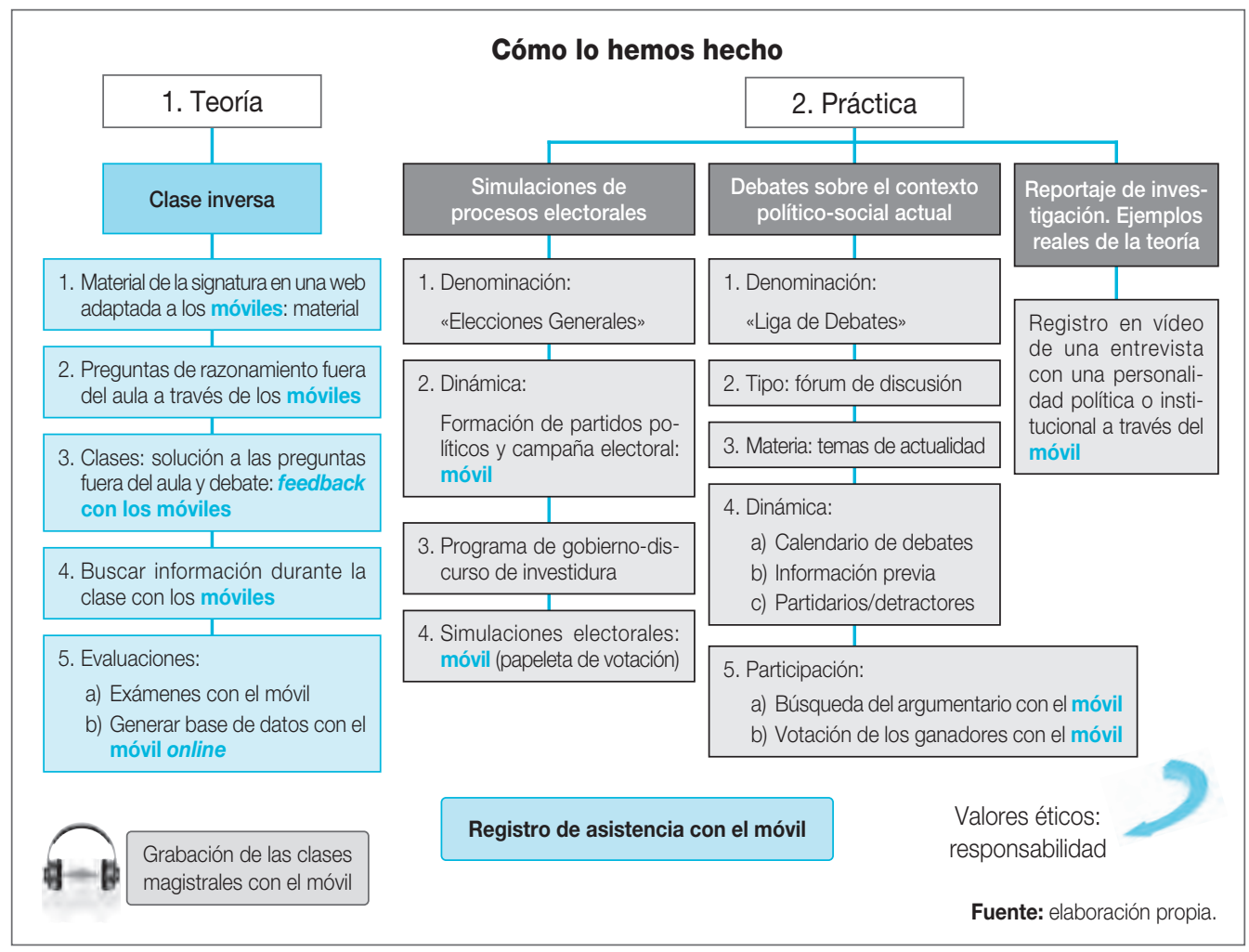




\subsection{Parametrización de datos}

Con la información aportada por la app se ha creado una base de datos Excel que permite un seguimiento detallado de la trayectoria evolutiva en el aprendizaje del estudiante, así como generar tutorías inteligentes destinadas al alumnado cuya evolución está por debajo de la media de la clase.

\subsubsection{Registro de asistencia}

El registro Excel de asistencia nos ha permitido visualizar un gráfico con los porcentajes de asistencia diarios y globales, fijar unos umbrales mínimos y cambiar actitudes o pautas si se traspasan, a la vez que puede ser un complemento evaluativo, si se considera oportuno (véase figura 3).

Figura 3. Gráfico de asistencia. Un umbral permite modificar actitudes o pautas en caso de que la asistencia decrezca. Parametrización y análisis de datos de asistencia

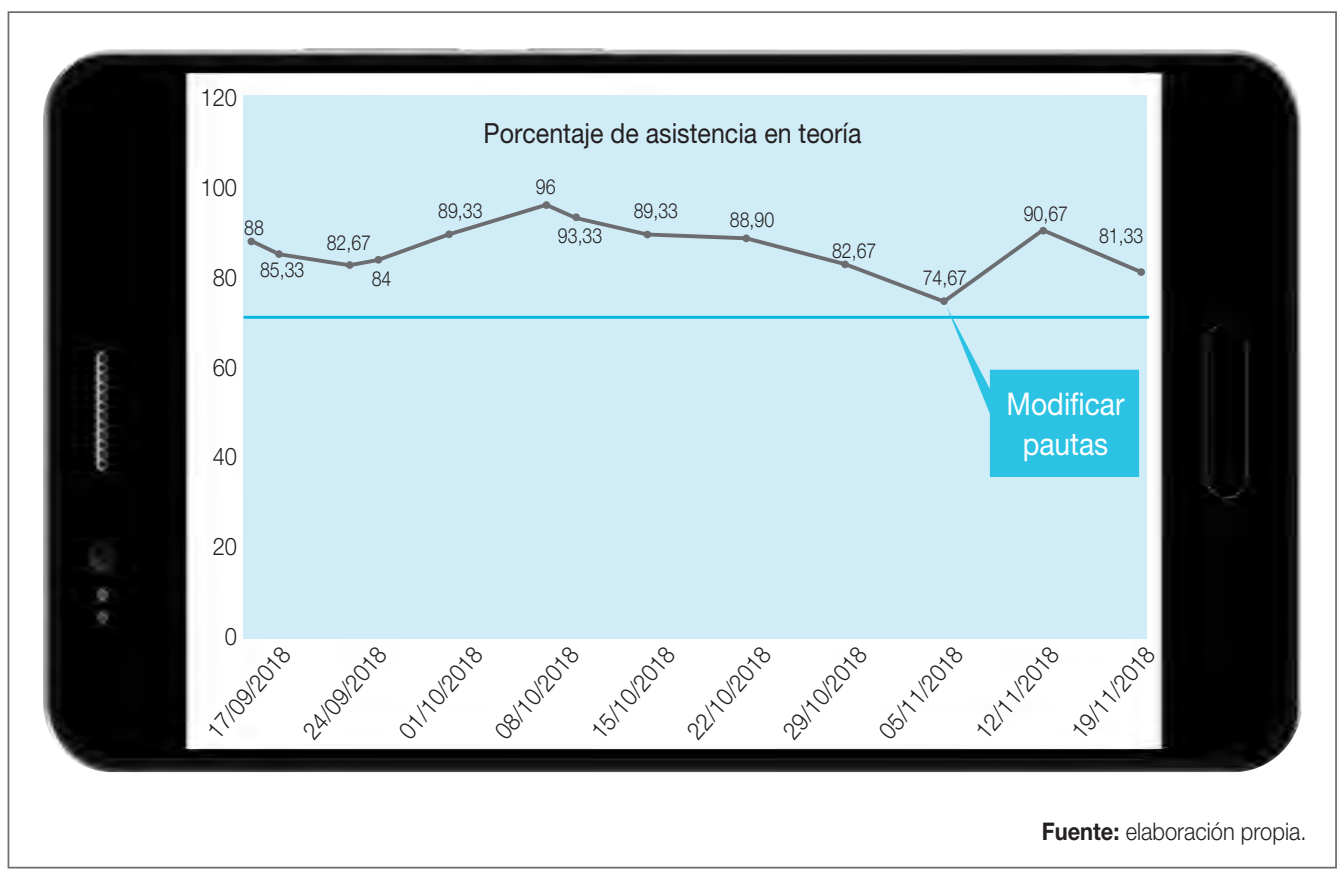

\subsubsection{Registro de resultados del test fuera del aula}

Con la clase inversa se obtiene el resultado del test que el alumnado contesta antes de la clase. La app genera automáticamente una hoja Excel para el docente. Los parámetros aportan información sobre el grado de comprensión del tema, la celeridad en la respuesta, 
los aciertos y los errores de cada estudiante. Los aciertos, la diligencia o la dejadez reiterada de cada estudiante permiten ver una evolución individualizada e interactuar con el alumnado menos predispuesto (véase cuadro 2).

Cuadro 2. Base de datos que generan los test fuera del aula. Parametrización y análisis de datos de la clase inversa

\section{Resultado de los test fuera del aula}

Derecho: Tema 2. El constitucionalismo histórico (Mañana [10/10/2018]-Clase inversa-Preguntas test)

\begin{tabular}{|c|c|c|c|c|c|c|}
\hline Orden de contestación & Estudiantes & Puntos & Respuestas c & rrectas & Respl & tas incorrectas \\
\hline 1 & $x x x x x$ & 9 & 9 & & & 1 \\
\hline 2 & $x x x x x$ & 9 & 9 & & & 1 \\
\hline 3 & $x X X X X$ & 9 & 9 & & & 1 \\
\hline 4 & $x X X X X$ & 8 & 8 & & & 2 \\
\hline 5 & $x x x x x$ & 7 & 7 & & & 3 \\
\hline 6 & $x x x x x$ & 7 & 7 & \multirow{3}{*}{\multicolumn{2}{|c|}{$\begin{array}{c}\text { Interacción con } \\
\text { los estudiantes } \\
\text { menos } \\
\text { diligentes... }\end{array}$}} & 3 \\
\hline 7 & $X X X X X$ & 6 & 6 & & & 4 \\
\hline 8 & $x x x x x$ & 5 & diligentes... & & & 5 \\
\hline 9 & $x X X X X$ & 4 & \multicolumn{3}{|l|}{4} & 6 \\
\hline 10 & $X X X X X$ & 3 & \multicolumn{3}{|l|}{3} & 0 \\
\hline
\end{tabular}

Fuente: elaboración propia

\subsubsection{Registro de los resultados de los test quincenales}

Después de cada examen, la app genera automáticamente una hoja Excel con los porcentajes de aciertos de cada estudiante y la calificación obtenida, lo que facilita enormemente la corrección tradicional individualizada y el envío, al instante, de la nota al móvil.

\subsubsection{Tutorías inteligentes}

Una base de datos (véase cuadro 3) genera un gráfico evaluativo del estudiante con la comparativa de la media de la clase, lo que permite hacer tutorías cuando se da un progreso inadecuado y, a su vez, permite que el estudiante pueda realizar con el docente una simulación de nota (véase figura 4). 


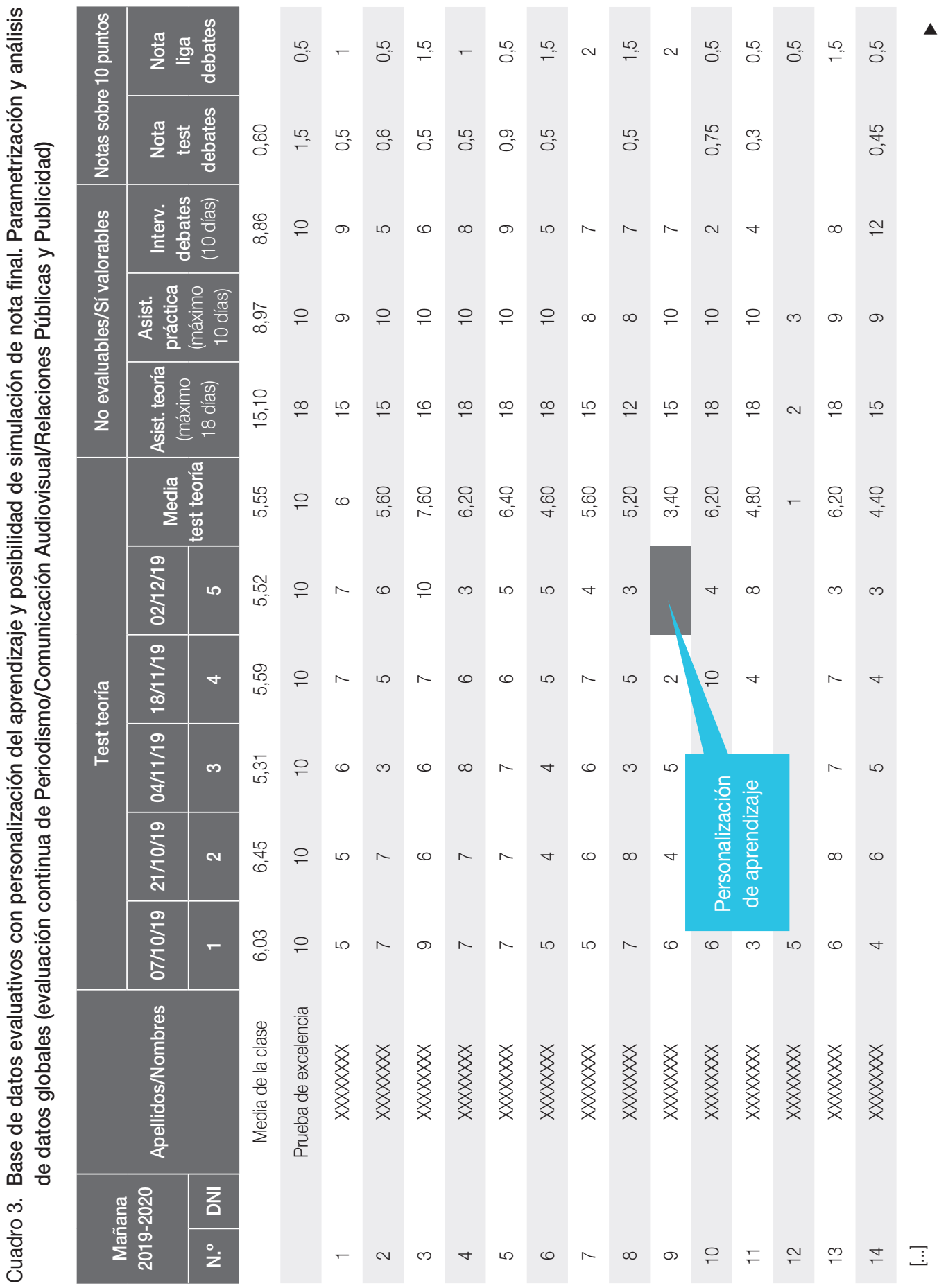



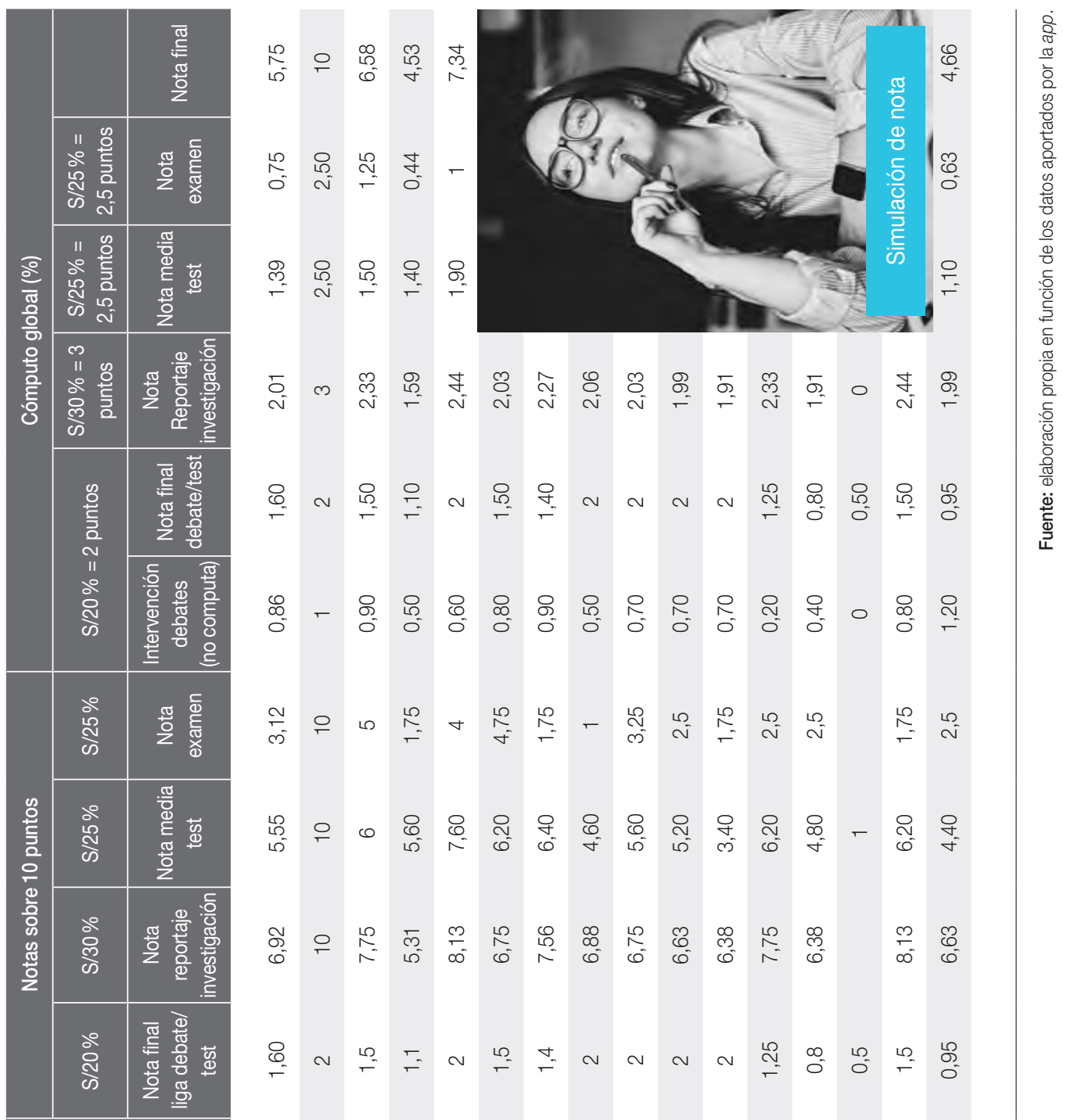

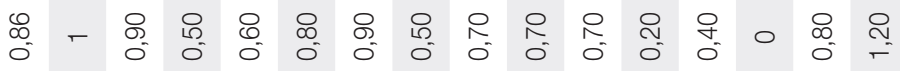

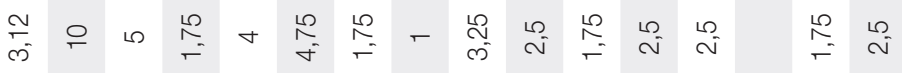

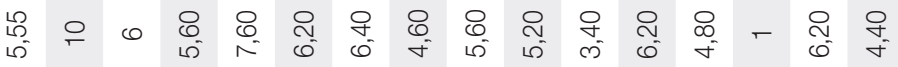

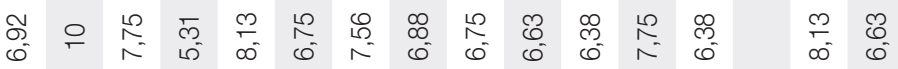

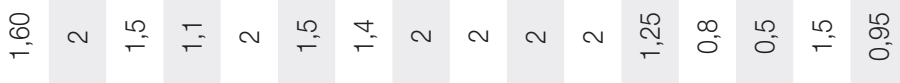
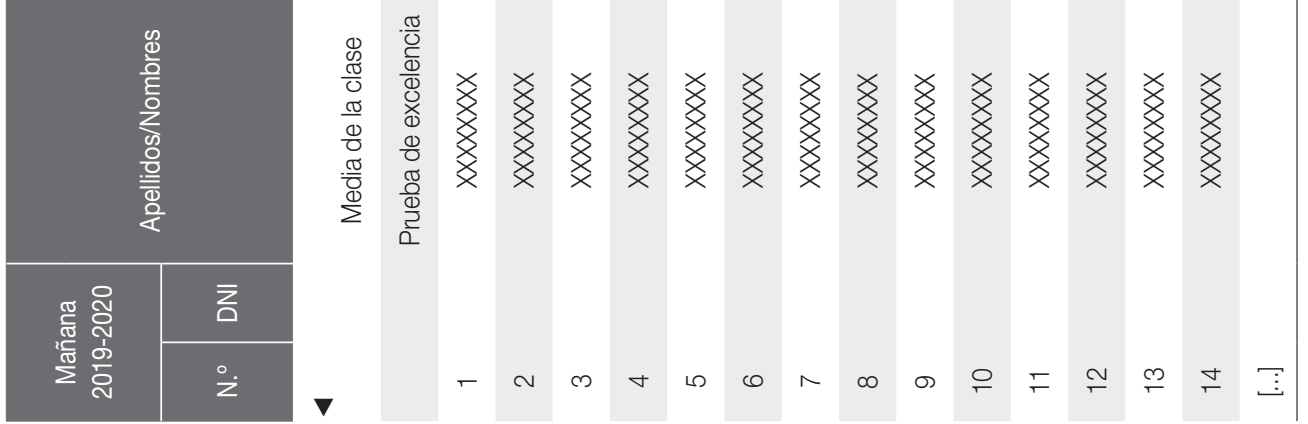
Figura 4. Gráfico evolutivo y comparativo de cada estudiante en relación con la media de toda la clase. Parametrización y análisis de datos individualizados

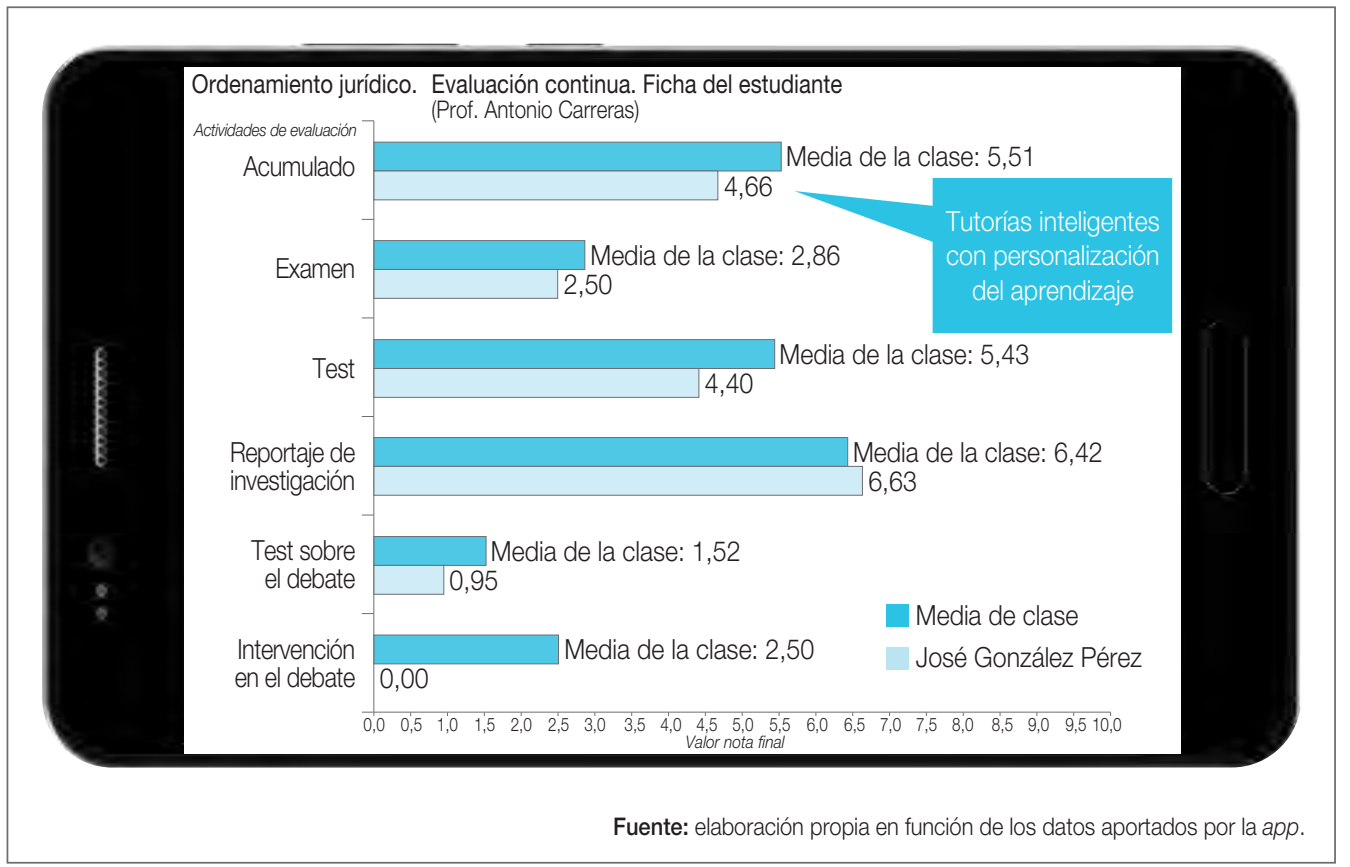

\subsection{Ventajas e inconvenientes del uso del móvil en el aula}

Con los resultados obtenidos y la experiencia adquirida durante estos cursos, podemos constatar empíricamente algunas de las fortalezas y debilidades ${ }^{2}$ (véase cuadro 4):

Cuadro 4. Fortalezas y debilidades del uso del móvil en el aula

\section{Fortalezas}

Aumento de la motivación y participación.

Más implicación del estudiante.

Clases más dinámicas, rompiendo rutinas.

Mejora la comprensión de la materia.

2 Véanse otras observaciones en Nasarre (2014). 


\section{Fortalezas}

Mejora el seguimiento individual del proceso evaluativo.

Facilita las pruebas evaluativas presenciales en tiempo y costes.

Facilita el trabajo autonómo y pruebas evaluativas virtuales.

Permite una educación tecnológica.

Reinventa la metodología.

Convierte el móvil en un recurso educativo.

\section{Debilidades}

Puede poner de manifiesto tecnologías discriminatorias entre estudiantes.

En alguna actividad evaluativa angustia a una minoría de estudiantes.

Hay que tener una alternativa en caso de que algunos dispositivos no estén operativos.

Posibilidades de copia en apps comerciales.

Fuente: elaboración propia.

\section{Diseño de una app personalizada y transversal}

Una vez verificada la bondad del uso de la app en el aula a través de los dispositivos móviles, comprobada su efectividad durante los cursos 2018-2019 y 2019-2020 en un colectivo de 421 estudiantes y vistas las ventajas e inconvenientes de esta herramienta, hemos analizado las apps comerciales del mercado, hemos valorado la posibilidad de creación de una nueva app y hemos pautado, diseñado y desarrollado durante el curso 2019-2020 una nueva app personalizada y transversal.

\subsection{Apps comerciales para la docencia universitaria}

Las posibilidades de la utilización de los dispositivos móviles en la docencia ha comportado la aparición de varias apps que cumplen razonadamente las necesidades docentes. Son apps creadas fuera de nuestro entorno y adaptadas a los planes educativos de otros países y, por tanto, adaptables parcialmente en nuestro ámbito educativo y, generalmente, en ciclos de enseñanza no universitaria. Muchas de estas apps están en el mercado de forma gratuita, son más o menos intuitivas y amigables, con espacio limitado en su forma gratuita y con un coste más elevado en sus diferentes modalidades de capacidad y funciones. Se pueden descargar rápidamente a través de iTunes o Apps Store. Sin embargo, las apps comerciales gratuitas están limitadas en cuanto a su capacidad, no acaban de adaptarse a las necesidades del docente y no permiten una personalización institucional, y, lo que es más importante aún, son plataformas que escapan al control de los datos y accesibilidad. Las principales apps, de las que hemos analizado sus debilidades y fortalezas (análisis DAFO), son: 


\section{A) Kahoot! (https://kahoot.com/)}

- Descripción. Es una plataforma gratuita creada en Noruega en 2013 que permite realizar actividades evaluativas y de sondeo de opiniones. Ha sido ideada para el aprendizaje a través del juego (gamificación).

- Funcionamiento. El profesorado puede crear preguntas, encuestas, conceptos para ordenar, trabajos en grupo y trabajos fuera del aula. La pregunta puede aparecer en la pantalla de la clase, no en el móvil. El estudiante accede a través de un pin que facilita el docente. Genera un fichero Excel con los resultados.

- Puntos fuertes. Podemos decir que es intuitiva, fácil de manejar, simple, lúdica y con una capacidad considerable en la versión gratuita, recortada en cuanto a posibilidades y opciones.

- Puntos débiles. Las preguntas del test quedan grabadas en los móviles de los estudiantes y les dan la solución al momento, lo que dificulta su uso como prueba evaluativa. Permite salir del aplicativo e ir a otras pantallas del móvil o hacer una captura de pantalla. Esto facilita la copia. También permite al alumnado ver los resultados de las calificaciones de toda la clase.

- Coste orientativo. La versión sencilla es gratuita. Los precios mensuales de otras versiones por docente usuario: Estándar (10 €), Pro (19€), 360 Plus (39€) y 360 Pro $(59 €)$ (según tarifas vigentes en cada momento).

- Viabilidad. Un inconveniente es que si se quieren reutilizar preguntas de exámenes realizadas a través de test en Kahoot! para otras pruebas evaluativas, estas preguntas y sus respuestas quedan almacenadas en los móviles de los estudiantes, cosa que invalida estas preguntas para otros test, ya que los estudiantes tienen las repuestas correctas. No parece tener utilidad para actividades evaluativas en las que se pretenda conservar las preguntas para otros exámenes, ya que tanto las preguntas como las respuestas quedan guardadas en los móviles de los estudiantes. También podemos decir que presenta pocas medidas anticopia ${ }^{3}$.

\section{B) Nearpod (https://nearpod.com/)}

- Descripción. Es una plataforma educativa ideada en EE. UU. en 2012 que permite crear lecciones interactivas con los estudiantes y plantear preguntas.

- Funcionamiento. El docente puede agregar actividades con preguntas abiertas, buscar respuestas emparejadas, cuestionarios, dibujar, trabajos grupales, encuestas, completar espacios de un texto, incluir un PowerPoint con preguntas

3 https://www.capterra.es/software/156399/kahoot 
intercaladas y un memotest. Un código pin da acceso a los estudiantes. El docente recibe un reporte con los resultados.

- Puntos fuertes. Es intuitiva, sencilla, permite crear diversas actividades, las respuestas a las preguntas aparecen en la pantalla de los móviles y en la de la clase, no salen las respuestas correctas en los móviles, aporta archivos y gráficos de las respuestas, etc.

- Puntos débiles. Solo permite 40 usuarios, el tamaño de cada lección es de 20 MB, es poco amigable visualmente, requiere un ancho de banda considerable en el aula, ya que su sincronización es lenta, y los archivos que recibe el profesorado son en PDF y no en Excel.

- Coste orientativo. Versión gratuita limitada a 40 usuarios y 20 MB por lección. Versión Gold: 8,28 euros al mes o 99,44 euros al año con 50 usuarios y 40 MB por lección (según tarifas vigentes en cada momento).

- Viabilidad. Es útil para los PowerPoint interactivos con preguntas intercaladas. La capacidad de usuarios es muy limitada, así como los $20 \mathrm{MB}$. No es tan competitivo como Kahoot! y no lleva sonido incorporado 4 (Nasarre, 2014).

\section{C) Mentimeter (https://www.mentimeter.com/)}

- Descripción. Plataforma creada en Suecia en 2014 que permite interactuar con comentarios en tiempo real, con presentaciones, encuestas, lluvia de ideas y otras actividades de grupo.

- Funcionamiento. El docente crea varias preguntas, encuestas, respuestas abiertas, nube de palabras, sondeo de opiniones, etc. Un pin da acceso a los usuarios y las respuestas salen en la pantalla del aula.

- Puntos fuertes. Múltiples tipos de preguntas y funciones interactivas, intuitiva y fácil de usar.

- Puntos débiles. Limitación de preguntas y pruebas, no genera ficheros automáticos y el entorno no es demasiado amigable.

- Coste orientativo. Versión gratuita muy limitada: 2 preguntas y 5 pruebas por sesión. El precio de la versión Básica es 8,29 euros. El precio mensual de la versión ilimitada Pro es de 20,74 euros (según tarifas vigentes en cada momento).

- Viabilidad. La versión gratuita no permite muchos usuarios ni tiene capacidad 5 .

\footnotetext{
4 https://www.capterra.mx/software/122875/nearpod

5 https://www.capterra.mx/software/160936/mentimeter
} 


\section{D) Socrative (https://www.socrative.com/)}

- Descripción. Aplicación nacida en EE. UU. en 2010. Es un gestor de participación de los estudiantes en el aula en tiempo real.

- Funcionamiento. Destaca por las preguntas tipo cuestionario, respuestas verdadero/falso, preguntas cortas, trabajos fuera del aula y de aprendizaje colaborativo. Permite enfrentamiento de equipos de trabajo competitivos.

- Puntos fuertes. Posibilidad de utilizar un fichero Excel para importar preguntas. Permite competitividad entre equipos e incorporar preguntas sobre la marcha.

- Puntos débiles. No tiene opción de proyección en pantalla del aula.

- Coste orientativo. Existen una versión gratuita para 50 estudiantes. El precio de la versión Pro para docentes es de 46,46 euros y el de la versión Pro Superior, por 150 usuarios, es de 82,86 euros (según tarifas vigentes en cada momento).

- Viabilidad. La poca capacidad de usuarios restringe su uso6.

Cuadro 5. Fortalezas, debilidades y coste de las apps comerciales

\section{Fortalezas}

Garantía de funcionamiento probada. No hay periodo de prueba.

Cubre las necesidades básicas estandarizadas.

Cada app es buena para lo que está creada.

Algunas están adaptadas para incluir patrocinadores y logos.

\section{Debilidades}

A pesar de su bondad, ninguna se adapta a las necesidades propias.

Hay aspectos que no las hacen viables (facilidad de copia, invalida el mismo test para sucesivas ocasiones

al quedar rastro en los móviles, etc.).

Poca adaptabilidad. No se puede crecer en nuevas ideas.

Poca capacidad en las versiones gratuitas.

Su base de datos no está bajo el control de la universidad.

Inseguridad como plataforma de accesibilidad y control.

\section{Coste}

Costes anuales en función de los participantes, capacidad MB y nivel de apps.

6 https://www.capterra.com/p/172761/TurningPoint/ 


\subsection{Ventajas e inconvenientes de una app de nueva creación}

Una vez realizado el análisis DAFO de las apps comerciales, hicimos lo mismo ante un supuesto de app de desarrollo propio, viendo en esta muchas más fortalezas que debilidades (véase cuadro 6).

\section{Cuadro 6. Fortalezas, debilidades y coste de la app de nueva creación}

\section{Fortalezas}

Seguridad de bases de datos de carácter personal y accesibilidad.

Adaptable a las necesidades de cada facultad/universidad.

Facilidad de modificación y mantenimiento.

Posibilidades de crecimiento con nuevas ideas.

Almacenamiento de datos en servidores de la propia universidad.

Adaptada a los patrocinadores y logos.

Debilidades

Diseñar, desarrollar y periodo de prueba.

Necesidad de un servidor.

Licencias anuales de Oracle.

\section{Coste}

No hay cuotas anuales excesivas, solo mantenimiento del servidor y licencias.

Coste inicial elevado.

Fuente: elaboración propia

Ante estos factores decisorios, planteamos unos condicionantes que son indispensables para que una app pueda empezar a ser desarrollada, inspirados en las fortalezas de las apps comerciales y en nuestra propia experiencia (véase cuadro 7).

Cuadro 7. Objetivos básicos de una app de nueva creación

Parámetros que hay que definir

La app debería estar homologada para iOS, Android y tener una página web.

Contemplar un cortafuego (firewall) contra virus maliciosos. 


\section{Parámetros que hay que definir}

Ser adaptable a las características de cada facultad/universidad.

Incluir logos de posibles patrocinadores.

Sencilla, amigable, intuitiva, rápida, etc.

Capacidad de almacenamiento suficiente.

Adaptable a los sistemas informáticos de la universidad (por ejemplo, Moodle).

Dos niveles de usuarios (docentes/estudiantes) y administrador autorizado.

Posibilidad de crecimiento y modificaciones sencillas para administradores.

Entrega de los códigos fuentes a la facultad/universidad.

Cuantificar el coste y el tiempo de implementación.

Fuente: elaboración propia.

Como se puede ver, la creación ex novo de esta app conlleva una mayor flexibilidad de modificación, crecimiento y control, argumentos suficientemente sólidos a la hora de tomar decisiones.

\subsection{Pautas para la creación de la nueva app}

Con este análisis y con nuestra experiencia estuvimos en disposición de analizar y diseñar una app de nueva creación. El propósito de este diseño se basó en conseguir una nueva app transversal, que fuera adaptable a diferentes facultades y universidades y que aportara múltiples ventajas para el docente, estimulándole para dar una respuesta a los retos tecnológicos actuales e innovar en el planteamiento de las metodologías docentes en el ámbito universitario.

Los ítems específicos del proyecto han sido los siguientes:

- Analizar algunas de las app para dispositivos móviles que existen en el ámbito de las TIC.

- Diseñar la parametrización de una app propia con las funciones personalizadas.

- Cuantificar los costes económicos y humanos para la creación.

- Explorar la vía del micromecenazgo para asumir los costes y una beca-proyecto para ayudar a su desarrollo.

- Desarrollar una app por un equipo informático profesional.

- Implementación práctica de la app en la docencia y formación del profesorado.

- Adaptable a los sistemas informáticos de la universidad (Moodle, etc.). 


\subsection{Diseño y parametrización de la app de nueva creación}

Atendiendo a estas pautas, la app que se ha diseñado incluye diferentes funciones y contenidos: presentaciones (PowerPoint) con test interactivo, pruebas evaluativas presenciales y virtuales, registro de asistencia, procesos participativos y función para congresos y jornadas (en construcción), y otros eventos pertinentes.

Además, la app permite la esponsorización del producto, en una primera pantalla, lo que posibilita económicamente su creación y mantenimiento. La descarga de Play Store o Apple Store será gratuita para docentes y estudiantes.

\subsubsection{Funciones y contenidos}

\section{A) Función para presentaciones interactivas}

Función pensada para que el profesorado pueda sondear la comprensión de los contenidos a medida que va exponiendo la clase magistral y para que rompa la monotonía de las sesiones largas, estimule el debate y la competitividad y avance progresivamente en el aprendizaje (feedback). Se ha diseñado una batería de preguntas para cada tema que se intercalan en el PowerPoint cada 30 minutos. Son preguntas de opción múltiple, de definición y contenido corto o pequeños comentarios de texto que el alumnado responde con resultados gráficos en la pantalla del aula. También se puede adaptar a las clases prácticas con comentarios de textos, supuestos de hecho, vídeos etc.

Parametrización:

a) El docente diseña el PowerPoint intercalando dos o tres preguntas al final de cada apartado importante de la lección. Lo cuelga en una carpeta de la app.

b) Tipo de preguntas: test con preguntas de opción múltiple, preguntas cortas, pregunta abierta (encuesta), preguntas tipo verdadero/falso, pequeño texto para hacer comentarios con respuestas seleccionadas, ordenar conceptos, etc.

c) Al empezar la clase, el docente accede a la carpeta de la app donde está el fichero creado de la lección correspondiente y lo activa.

d) Un código (pin) dará acceso a los estudiantes como contraseña para cada sesión.

e) El estudiante accede al PowerPoint a través de su móvil y ve cómo avanza la explicación y las preguntas planteadas por el docente.

f) Los estudiantes no deben ver la respuesta hasta que toda la clase finalice la pregunta. 
g) El estudiante elige la opción entre las posibles respuestas dentro de un tiempo predeterminado por el docente.

h) Agotado el tiempo, aparece en la pantalla del aula un gráfico con el total de respuestas correctas e incorrectas. El docente ve el grado de asimilación de los estudiantes, lo que le permite seguir la explicación o volver a explicar los contenidos no comprendidos por la mayoría del alumnado.

i) Al finalizar se genera un fichero Excel con el resultado individualizado para cada estudiante que es remitido automáticamente al docente.

j) No deberá dejar registro del PowerPoint en los móviles de los estudiantes (opcional por parte del docente). En todo caso, el alumnado no debe ver las respuestas del resto de la clase.

k) La app tiene que tener capacidad de almacenamiento de datos suficiente como para archivos de PowerPoint (3,2 MB).

\section{B) Función para pruebas evaluativas}

Función que permite realizar online diferentes pruebas evaluativas con los móviles. Un control de tiempo para las respuestas, un control anticopia y un indicador de abandono momentáneo del aplicativo prevendrán el fraude de copia.

Parametrización:

a) El docente genera una batería de preguntas con un tiempo de contestación determinado o libre que lo archiva como fichero en la carpeta de la app.

b) Tipo de preguntas: test de opción múltiple (máximo 4 preguntas), preguntas cortas, preguntas tipo verdadero/falso, pequeño texto para hacer comentarios con respuestas seleccionadas, proyección de imagen/vídeo con respuestas y ordenar conceptos.

c) El docente accede al fichero de la prueba correspondiente de la app y lo activa.

d) Un código (pin), que solo aparece en la pantalla del aula, dará acceso a los estudiantes como contraseña para introducir sus datos en cada sesión.

e) El estudiante introducirá sus datos (apellidos y nombre, documento nacional de identidad [DNI], etc.).

f) El docente activará la prueba con un segundo pin de comienzo que se podrá visualizar solamente en la pantalla del aula.

g) Las preguntas se verán exclusivamente en la pantalla del aula.

h) En cada uno de los dispositivos móviles únicamente aparecerán las posibles respuestas ( $a, b, c$ y d), así se evita que el estudiante pueda hacer una copia de pantalla del móvil con las preguntas e invalidar el test para otras ocasiones. 
i) Solo debe permitir un intento de contestación (para evitar duplicidad). Dará como válida la última respuesta.

j) Barrera anticopia. La app detectará los dispositivos móviles que cambien de pantalla una vez introducido el primer pin y antes de activar el segundo pin, así como durante la prueba (para evitar que el estudiante envíe el código a otros compañeros fuera del aula). El abandono momentáneo de la aplicación será interpretado como «fraude» y generará un listado para el docente con el alumnado que ha abandonado la aplicación durante la prueba evaluativa.

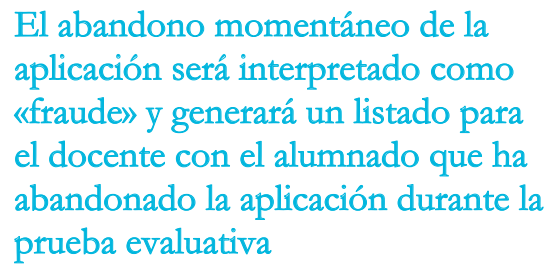
aplicación será interpretado como «fraude» y generará un listado para el docente con el alumnado que ha abandonado la aplicación durante la prueba evaluativa

k) Las respuestas serán aleatorias en cada dispositivo móvil para evitar la copia de los compañeros de ambos lados de la mesa.

I) Para mayor seguridad y para evitar el acceso a la prueba de estudiantes que estén fuera del aula, se podrá habilitar un sistema de detección de proximidad por IP, bluetooth, GPS, código QR, NFC.

m) Las respuestas generarán automáticamente un listado (Excel) con las preguntas correctas, las incorrectas, la correspondiente evaluación y estadísticas, que será remitido automáticamente al docente.

n) No deberá dejar residuo en los móviles de los estudiantes (no deben poder ver los resultados globales en sus dispositivos móviles y se borrarán las respuestas).

ñ) El listado se podrá visualizar en la pantalla del aula para saber los resultados (total de preguntas correctas e incorrectas y resultados).

\section{C) Función para pruebas evaluativas fuera del aula}

Esta función deberá permitir programar trabajos y evaluaciones fuera del aula (comentarios de texto, preguntas de asimilación o comprensión, etc.) a fin de poder realizar actividades evaluativas adaptadas a la clase inversa (flipped classroom o flip teaching). Para ello las preguntas planteadas por el docente han de ser de razonamiento. Es importante que la app permita el trabajo autónomo del alumnado y la posibilidad de evaluación a distancia (virtual). Un ejemplo lo tenemos en las necesidades virtuales surgidas a raíz del impacto de la COVID-19.

\section{Es importante que la app permita el trabajo autónomo del alumnado y la posibilidad de evaluación a distancia (virtual). Un ejemplo lo tenemos en las necesidades virtuales surgidas a raíz del impacto de la COVID-19}


Parametrización:

a) El docente genera las preguntas y archiva el fichero en la carpeta de la app. También puede generar un banco de preguntas para su uso aleatorio.

b) Tipo de preguntas: tipo test con preguntas de opción múltiple, preguntas cortas, preguntas abiertas (encuesta), preguntas tipo verdadero/falso, pequeño texto o imagen para hacer comentarios con respuestas seleccionadas, o batería de test para que los estudiantes practiquen.

c) El docente comunica al alumnado una fecha de inicio y una hora límite de contestación (unos días antes de comenzar la clase en el supuesto de flipped classroom), así como un primer pin de acceso para introducir sus datos.

d) A la hora indicada, el docente envía un segundo pin de inicio de la prueba. Los estudiantes contestan a las preguntas que salen por la pantalla de sus dispositivos móviles. Si el estudiante abandona la aplicación momentáneamente, se interpretará como «fraude», generando un listado de abandonos. Se aplicará el sistema anticopia expuesto anteriormente (véase letra j) del apartado «B. Función para pruebas evaluativas»).

e) Solo debe permitir un intento de contestación (para evitar duplicidad). Dará como válida la última respuesta.

f) Aleatoriedad: para poder utilizar preguntas aleatorias de un banco de preguntas creado por el docente. Las preguntas y las respuestas han de aparecer en orden diferente para cada estudiante.

g) A la hora fijada de finalización (antes de impartir la clase en los supuestos de flipped classroom), la aplicación no permitirá más respuestas y generará un archivo Excel para el docente con la relación de los estudiantes y sus respuestas acertadas, las no acertadas, el orden cronológico de contestación y la nota.

h) En los supuestos de flipped classroom, el docente detecta antes de la clase el grado de respuestas asimiladas y las que no, lo que le permitirá incidir en los conceptos confusos.

i) Siempre a voluntad del docente, podrá o no dejar residuo en los móviles de los estudiantes.

\section{D) Función para control de asistencia}

Permitirá el registro de asistencia a clase, a conferencias, cursillos y otros eventos. Si se utiliza para el registro de los estudiantes en clase, conllevará unos controles más rígidos que en otro tipo de eventos. No sobrepasará los 3 minutos. 
Parametrización:

a) El docente introduce el número total de estudiantes matriculados, para obtener al final los porcentajes de asistentes, genera una pregunta y archiva el fichero en la carpeta de la app. La pregunta es alternativa o de respuesta presencial (por ejemplo: «Has asistido a la clase, cursillo, reunión... en fecha...»/Respuesta: «Sí»; $0 \ll 3+2$ es igual a...»/Respuesta: «5»), con un corto tiempo de respuesta (1-7 segundos).

b) Selecciona la posibilidad de música o no (ludificación).

c) Un código (pin) que solo aparece en la pantalla del aula dará acceso a los estudiantes como contraseña. El aplicativo detectará la IP y su proximidad con los dispositivos móviles. También se puede utilizar la detección de proximidad por bluetooth, GPS, código QR, NFC, etc.

d) El estudiante introducirá sus datos por orden de apellidos y nombre como campos obligatorios. El DNI/número identificativo como campos optativos.

e) Se activará la sesión con un segundo pin que únicamente aparecerá en la pantalla del aula.

f) La pregunta solo se verá en la pantalla del aula.

g) El estudiante contestará la pregunta relacionada con la asistencia.

h) Solo deberá permitir un intento de contestación (para evitar duplicidad). Dará como válida la última respuesta.

i) Barrera antifraude. Se aplicará el sistema anticopia expuesto anteriormente (véase letra j) del apartado «B. Función para pruebas evaluativas»).

j) No debe dejar residuo en los móviles de los estudiantes.

k) La app generará un fichero Excel automático con la lista alfabética y los porcentajes de asistencia que será remitido al docente.

Parametrización para otros eventos que no requieran un control excesivo:

a) Los parámetros serán los mismos, pero no contemplará un segundo pin y la pregunta aparecerá en la pantalla del móvil del usuario.

\section{E) Función para votaciones}

Esta función permite captar opiniones, votaciones, sondeos, equipos ganadores, toma de decisiones, etc., de manera anónima o nominal. 
Parametrización:

a) El docente crea una pregunta que archiva en un fichero en la carpeta de la app.

b) Determina si debe ser con contestación anónima o nominal.

c) Selecciona la posibilidad de música o no (ludificación).

d) Un código pin, que solo aparece en la pantalla del aula, dará acceso a los estudiantes como contraseña para cada sesión.

e) En caso nominal, el estudiante introducirá sus datos por orden de apellidos y nombre como campos obligatorios. El DNI/número identificativo (optativos).

f) El docente activará la sesión con un segundo pin que únicamente aparecerá en la pantalla del aula.

g) Los estudiantes verán por la pantalla del móvil la pregunta y las respuestas.

h) El estudiante contestará la pregunta relacionada.

i) Solo deberá permitir un intento de votación (para evitar duplicidad). Dará como válida la última respuesta.

j) Barrera antifraude. Se aplicará el sistema anticopia expuesto anteriormente (véase letra j) del apartado «B. Funcion para pruebas evaluativas»).

k) No deberá dejar residuo en los móviles de los estudiantes (no deben poder ver los resultados globales en sus dispositivos móviles).

\section{F) Función para eventos interactivos (en fase de construcción)}

Esta función está pensada para congresos y jornadas, y su objetivo es dar información sobre el evento a través de los dispositivos móviles de cada participante, promocionar a patrocinadores, presentar ponencias y comunicaciones, documentación, encuestas en tiempo real, información sobre el congreso o la jornada, etc.

Con este diseño estuvimos en condiciones para abordar el desarrollo de la nueva app y avanzar en el proyecto de investigación.

\begin{abstract}
La función para eventos
interactivos (todavía en fase de construcción) está pensada para congresos y jornadas, y su objetivo es dar información sobre el evento a través de los dispositivos móviles de cada participante, promocionar a patrocinadores, presentar ponencias y comunicaciones, etc.
\end{abstract}




\section{Planificación económica, desarrollo e implantación}

\subsection{Planificación y cuantificación}

Una vez parametrizados las funciones y los requisitos, fue necesario realizar una planificación y cuantificación económica, buscar un mecenazgo para hacer frente al coste, formar un equipo de docentes y estudiantes y crear una beca-proyecto para el apoyo humano necesario.

\subsection{Cuantificar el coste}

Una empresa de desarrollos informáticos del mercado valoró los costes totales y por fases del proyecto a través de un presupuesto desglosado. La cuantificación resultante queda reflejada en el cuadro 8.

Cuadro 8. Coste aproximado en euros de creación de una app

\begin{tabular}{|c|c|c|c|c|c|c|c|c|c|c|c|}
\hline Funciones & Android & IOS & $\begin{array}{c}\text { Oracle } \\
(4 \%)\end{array}$ & $\begin{array}{l}\text { Oracle } \\
(15 \%)\end{array}$ & $\mathrm{F} 1$ & F2 & F3 & F4 & $\begin{array}{l}\text { Total } \\
\text { sin IVA }\end{array}$ & $\begin{array}{l}\text { IVA } \\
(21 \%)\end{array}$ & Total \\
\hline $\begin{array}{l}\text { 1. PowerPoint } \\
\text { interactivo }\end{array}$ & $3.488,8$ & $3.782,8$ & 1.176 & 441 & $8.888,6$ & & & & & $1.866,61$ & $10.755,21$ \\
\hline $\begin{array}{l}\text { 2. Pruebas eva- } \\
\text { luativas }\end{array}$ & 2.744 & 3.038 & & 441 & & 6.223 & & & & $1.306,83$ & $7.527,83$ \\
\hline 3. Asistencia & 2.548 & 2.842 & & 441 & & & 5.831 & & & $1.224,51$ & $7.055,51$ \\
\hline $\begin{array}{l}\text { Aplicación con- } \\
\text { gresos y jornadas }\end{array}$ & 3.626 & 3.920 & & 441 & & & & 7,987 & & $1.677,27$ & $9.664,27$ \\
\hline Total & & & & & & & & & $28.929,60$ & $6.075,22$ & $35.004,82$ \\
\hline
\end{tabular}

Fuente: elaboración propia en función de presupuestos solicitados a empresas informáticas del mercado.

Estos costes de desarrollo son orientativos a efectos comerciales. Sin embargo, si la universidad tiene una Facultad de Ingeniería, puede ser una buena opción para su desarrollo; en nuestro caso, hemos contado con la colaboración del departamento de Informática de la ETSI para el desarrollo de esta app, con lo cual los costes se han reducido en un $50 \%$. 


\subsection{Micromecenazgo}

Cabe la posibilidad de que parte de este coste sea asumido a través de un micromecenazgo de alguna empresa privada, mediante un convenio de colaboración anual entre la universidad y la empresa (industria, banca, otros sectores privados o públicos). La contraprestación de la universidad en este caso sería la oferta de esponsorización de la app, donde el logotipo o razón social de la empresa colaboradora figurase en un lugar destacado de las páginas de la app, según convenio. Con esta fórmula se aprovecharía la sinergia de la aportación de la facultad/universidad con la que, al mismo tiempo, pueda hacer la empresa privada o pública, según se disponga. En nuestro caso, el proyecto ha sido costeado por una aportación personal realizada por un profesor (el que suscribe) que ha destinado un premio otorgado de 20.000 euros al desarrollo de esta app y a la beca-proyecto social.

\subsection{Creación de una beca-proyecto}

Dado que la implementación de esta app supone una tarea de trabajo a veces poco asumible por el profesorado que la lidera, se ha creado una beca-proyecto de Asistente de Innovación y Mejora Docente, dotada por una aportación del micromecenazgo.

Con esta beca-proyecto se ha pretendido conseguir dos objetivos, uno de soporte y otro social, es decir, contar con el apoyo de un estudiante para el desarrollo del diseño e implementación de la app y dotarla de un componente social,

Esta beca-proyecto tiene como objetivo facilitar la realización de los estudios de una estudiante (mujer) vulnerable económicamente, perteneciente a las minorías étnicas más desfavorecidas en el ámbito universitario, y procurar la igualdad ante la discriminación por motivo de nacimiento, raza, sexo y religión dado que tiene como objetivo facilitar la realización de los estudios de una estudiante (mujer) vulnerable económicamente, perteneciente a las minorías étnicas más desfavorecidas en el ámbito universitario, y procurar la igualdad ante la discriminación por motivo de nacimiento, raza, sexo y religión (colectivos de mujeres musulmanas, etnia gitana, etc.) (véase cuadro 9).

Cuadro 9. Características y requisitos de la beca

Tareas que se van a desarrollar

Colaborar en la investigación y aplicación de la innovación y mejora docente.

Análisis de metodologías docentes.

Apoyo en la implementación de la app de docencia para dispositivos móviles. 
Estudio de mercado de las diferentes apps para la docencia universitaria.

Asesorar y ayudar al profesorado en la implementación.

Integración de la app a los sistemas y aplicativos de la universidad (Moodle).

Apoyo al grupo de innovación docente de la facultad.

\section{Patrocinio}

Micromecenazgo: privado, en nuestro caso, o también entidades bancarias, industria, Administración pública, con compensación de esponsorización en la app.

\section{Características}

Dirigida a estudiantes (mujeres) de la facultad correspondiente con:

- Necesidades económicas importantes y que requieran de una ayuda para cubrir los gastos de transporte, mantenimiento, estancia, etc.

- Mujeres de minorías étnicas vulnerables por razón de género, religión, raza, etc.

- Currículum (6 de nota media).

- Experiencia en innovación docente.

- Importe mensual: 300 euros.

- Horas de dedicación: 10 horas semanales.

- Periodo de trabajo: de septiembre a junio incluido (10 meses).

Fuente: elaboración propia.

\subsection{Colaboraciones}

\subsubsection{Implicación de departamentos y facultades}

Dada la dimensión y transversalidad de este proyecto no ha sido difícil conseguir el apoyo de los responsables de los distintos departamentos y facultades de la universidad (decanos, jefes de departamento, etc.). Para crear la app, también se ha recibido el apoyo de los responsables de informática, de Moodle, del Servicio de Recursos Educativos, así como de los correspondientes vicerrectores de la universidad y del equipo investigador de la ETSI. Todos ellos se han mostrado colaborativos en el proyecto para lograr su éxito.

\subsubsection{Equipo de trabajo}

Conscientes de que el proyecto requiere de un complejo conjunto de aportaciones y esfuerzo humano, fue necesaria la integración de varios roles, tanto de profesorado como de 
estudiantes (consultivo). Para ello fueron integrados en este equipo varios responsables de grados y facultades: el responsable de Estudios de Comunicación de la Facultad de Letras, el responsable de Relaciones Laborales y Empleo de la Facultad de Ciencias Jurídicas, el responsable de Derecho de la Facultad de Ciencias Jurídicas, el responsable de la ETSI, etc.; es decir, un equipo transversal y multidisciplinar que aportó visiones y necesidades diferentes. A su vez, se ha creado una comisión del Grupo de Innovación Docente (GID) ad hoc para llevar a cabo la implementación y formación de estas tecnologías al profesorado. También se ha contado con un equipo consultivo de estudiantes de diferentes facultades y cursos (Derecho, doble grado de Derecho y Relaciones Laborales y Empleo, Comunicación Audiovisual, Periodismo y Relaciones Públicas y Publicidad) para captar su opinión a la hora de definir los parámetros de la app, dado que, en definitiva, es uno de los usuarios finales a los que va destinado este proyecto.

\subsection{La nueva app «Gaudeamus Virtual Education»}

Una vez parametrizada, cuantificados los costes y obtenidos los recursos necesarios, la ETSI ha desarrollado la interfaz web en un entorno responsive para adaptarla a los dispositivos móviles (iOS y Android) y ordenadores. A su vez, a través de la Facultad de Ciencias Jurídicas, se ha elaborado la correspondiente normativa legal de protección de datos, privacidad, política de cookies y avisos legales. Con todo ello, la nueva app, denominada «Gaudeamus Virtual Education», ya ha sido implantada en el curso 2020-2021, aportando diversas ventajas para el docente, el centro y el alumnado (véanse figuras 5 y 6 y cuadro 10).

Figura 5. Funciones de la app «Gaudeamus Virtual Education»

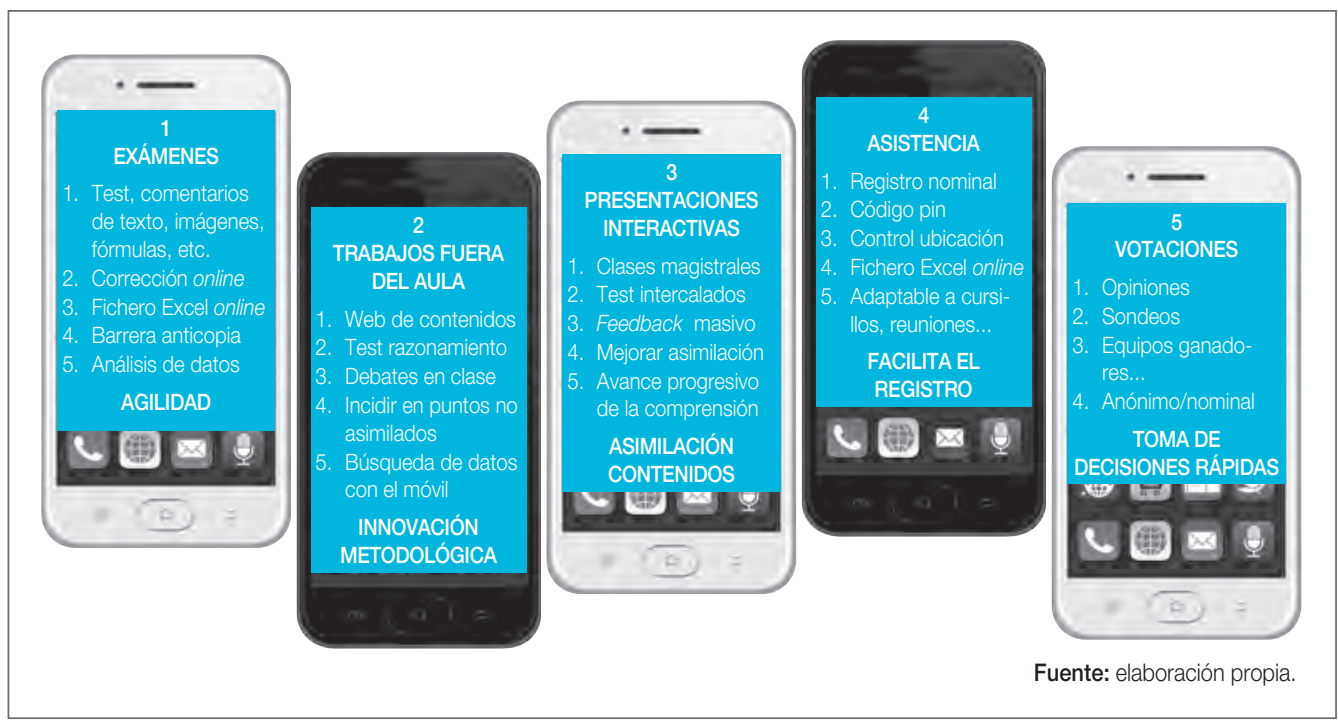


Figura 6. Menús iniciales desplegables de la app «Gaudeamus Virtual Education» (sencillos e intuitivos)
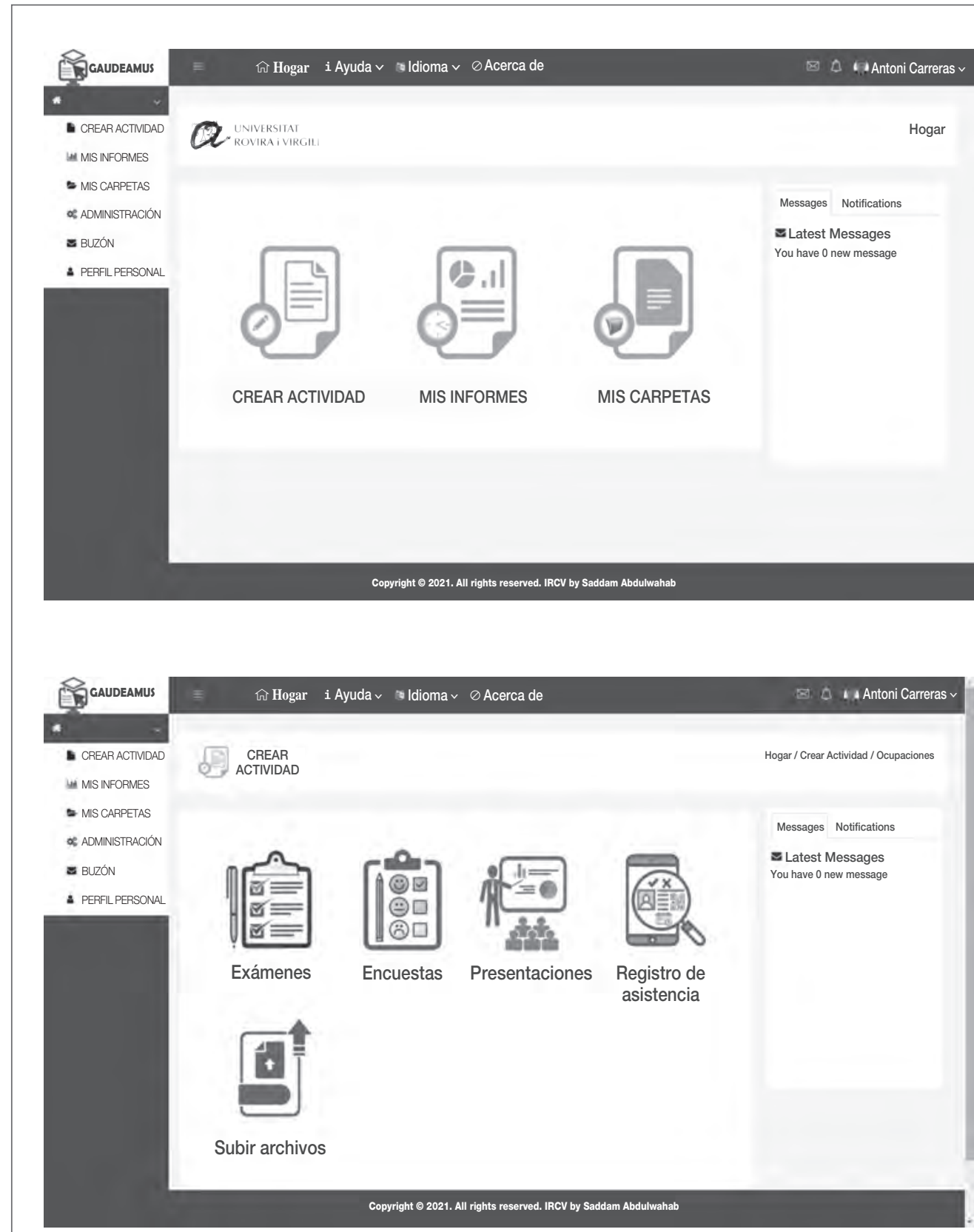


\section{Cuadro 10. Ventajas de la app «Gaudeamus Virtual Education»}

\section{Ventajas técnicas}

Facilidad de conexión.

Respuesta rápida.

Capacidad de almacenamiento adecuada.

Diseño amigable, juvenil, creativo, impactante y académico a la vez.

Manejo sencillo e intuitivo.

Seguridad de datos.

Permite incorporar logos de patrocinadores, generando recursos económicos.

Control absoluto de los datos y accesibilidad.

\section{Ventajas para el profesorado}

Facilita la realización de exámenes presenciales y virtuales al docente.

Fácil introducción de datos.

Permite diferentes tipos de exámenes (test, comentario de textos, imágenes, fórmulas, ordenar conceptos, verdadero/falso, etc.).

Fácil corrección.

Genera automáticamente cada nota y la compara con la media de la clase.

Rapidez en comunicar las notas a los estudiantes.

Genera una abundante base de datos que permite tutorías inteligentes.

Permite programar trabajos fuera del aula (homework) a través de la app del móvil. Clase inversa (flipped classroom), trabajo autónomo (impacto de la COVID-19).

Facilita la gestión de exámenes en las clases masivas.

Asegura una buena barrera anticopia.

Permite un control rápido de asistencia a clase, a cursos y a eventos.

Genera ficheros Excel adaptables a Moodle.

Es multilingüe.

\section{Ventajas para el centro}

Se adapta a la mayoría de las facultades y universidades.

Adapta las metodologías docentes a las nuevas tecnologías.

Elimina tiempo y costes de exámenes (lectores ópticos de exámenes).

Da una respuesta tecnológica al reto del uso de los móviles en el aula.

\section{Ventajas para el alumnado}

Mejora notablemente la asimilación de contenidos y los resultados finales.

Clases mucho más dinámicas y mayor participación en las preguntas. 


\section{Ventajas para el alumnado}

Tutorías individuales: simulaciones de nota final y progreso inadecuado.

Facilita el trabajo autónomo.

Respuesta rápida de sus calificaciones.

Ludificación y gamificación con componente musical.

Mayor motivación.

Fuente: elaboración propia.

\section{Criterios institucionales en los que se puede enmarcar este método}

\subsection{Alineación con los planes estratégicos de la universidad}

Se ha intentado adecuar el proyecto a los planes estratégicos de la Universidad Rovira i Virgili de Tarragona a través de su adaptación al plan de igualdad, al compromiso con los valores, a la capacidad de mejora en el ámbito disciplinario y al plan estratégico de investigación e innovación.

\subsubsection{Plan de igualdad}

Con el interés de facilitar la realización de los estudios y, a la vez, favorecer una mayor integración de la mujer perteneciente a las minorías étnicas más desfavorecidas en el ámbito universitario y procurar la igualdad por razón de la no discriminación por motivo de nacimiento, raza, sexo y religión, se ha contemplado la Beca del Proyecto de Innovación y Mejora, destinada a aquellas estudiantes vulnerables económicamente y con exclusión por su condición de colectivo femenino musulmán o de etnia gitana en las que la consecución de sus estudios puede representar un punto de inflexión en su vida personal. Así se ha incorporado una persona que reúne estas características en las tareas de diseño de esta app.

\subsubsection{Compromiso con los valores}

Uno de los objetivos de nuestra docencia ha sido y es mantener un compromiso con los valores, tal como ha quedado reflejado en las competencias marcadas. La participación de todos los estudiantes en la toma de decisiones a través de votaciones anónimas con los 
móviles ha puesto de manifiesto su grado de compromiso ético, de responsabilidad, de honradez y de honestidad, reflejado en sus decisiones. Este componente ha permitido ejemplificar la necesidad de mantener estos valores a la vez que formar a personas y miembros de una sociedad democrática. También se ha incidido en el uso racional del móvil para combatir el llamado phubbing, aprendiendo a hacer un buen uso de la tecnología móvil y a ser pioneros en contribuir en la construcción de una sociedad en la que el rol del móvil se convierta en una estructura generadora de conocimiento y no en un objeto de distracción. (Alineación con el plan estratégico: Plan Estratégico de la Tercera Misión. Compromiso con los Valores).

\subsubsection{Capacidad de mejora e innovación en el ámbito disciplinario}

La introducción del móvil en el aula le abre al profesorado un mundo de posibilidades que suelen ser muy bien recibidas por el alumnado. Permite una innovación metodológica, un mayor dinamismo y participación, y, en este aspecto, hay que recordar aquella frase de B. Franklin que dice «Dime y lo olvido, enséñame y lo recuerdo, involúcrame y lo aprendo».

En definitiva, el uso del móvil como recurso educativo permite innovar, mejorar la calidad del aprendizaje y la evaluación. (Alineación con el plan estratégico: Plan Director para la Reestructuración de la Oferta Docente de Grado, Máster y Doctorado).

\subsubsection{Segundo Plan Estratégico de Investigación e Innovación}

Con este método creemos haber invertido la función de los dispositivos móviles en el aula, ya que han pasado de ser una herramienta infrautilizada y molesta a un instrumento con mucho potencial dentro de las TIC, el cual permite estimular la innovación y el ensayo de nuevos métodos docentes adaptados a los dispositivos móviles (Segundo Plan Estratégico de Investigación e Innovación/Eje 4.2.3. Mejora de las herramientas TIC de apoyo a la I + I). A su vez, facilita la colaboración de patrocinadores en la app al incluir su logotipo, lo que permite potenciar el mecenazgo como herramienta para captar recursos destinados a la investigación e innovación. (Segundo Plan Estratégico de Investigación e Innovación/Eje 4.1.3. Potenciar el mecenazgo como herramienta para captar recursos destinados a la investigación y la innovación).

\section{Resultados obtenidos}

\subsection{Eficacia metodológica}

La experiencia con 421 estudiantes de dos facultades durante dos años, a los que se les han incorporado los dispositivos móviles en el aula, nos ha permitido ver su grado de 
eficacia en la metodología docente. Podemos afirmar que el uso de la app ha aumentado la motivación y la participación del alumnado, ha mejorado la comprensión de la materia, ha hecho las clases más dinámicas, ha facilitado el trabajo autónomo, ha ayudado al seguimiento individual del proceso evaluativo, ha permitido trabajar una educación tecnológica y ha convertido el móvil en un recurso educativo.
Podemos afirmar que el uso de la app ha aumentado la motivación y la participación del alumnado, ha mejorado la comprensión de la materia, ha hecho las clases más dinámicas, ha facilitado el trabajo autónomo, etc.

\subsection{Aceptabilidad y satisfacción por parte del alumnado}

Para constatar su grado de aceptabilidad y satisfacción por parte del alumnado, se ha realizado una encuesta a 333 estudiantes de las asignaturas que se han impartido con la utilización de los móviles. Los resultados de este sondeo han sido muy alentadores: los test virtuales fuera del aula (clase inversa) han obtenido una puntuación total de 8,20 ; las pruebas evaluativas en el aula, un 8,41; el registro de asistencia, un 9,08; y el uso del móvil en votaciones, un 8,31. En cuanto a la respuesta global de si se considera el móvil como una buena herramienta para hacer actividades docentes, la puntuación ha sido de un 8,70. También se ha testado el grado de valoración de los archivos de audio del profesor, registrados a través del propio dispositivo móvil y colgados en Moodle. Su aceptabilidad y valoración ha sido de 8,90 sobre 10 (véase cuadro 11).

Cuadro 11. Valoración del alumnado en relación al uso de los móviles en las actividades del curso

\begin{tabular}{|c|c|c|c|c|c|c|c|}
\hline \multirow{2}{*}{\multicolumn{2}{|c|}{$\begin{array}{l}\text { Facultad de Ciencias } \\
\text { Jurídicas }\end{array}$}} & \multicolumn{6}{|c|}{ Preguntas } \\
\hline & & Test fuera & Test en el & Asistencia & Votaciones & Buen & \\
\hline Derecho & $\begin{array}{c}\mathrm{N}^{\circ} \\
\text { encuestas }\end{array}$ & $\begin{array}{l}\text { Uso en la } \\
\text { clase inversa }\end{array}$ & $\begin{array}{c}\text { Prueba } \\
\text { evaluativa }\end{array}$ & $\begin{array}{l}\text { Móvil como } \\
\text { registro de } \\
\text { asistencia }\end{array}$ & $\begin{array}{l}\text { Dispositivo } \\
\text { de votación* }\end{array}$ & $\begin{array}{l}\text { Uso del } \\
\text { móvil en el } \\
\text { aula }\end{array}$ & $\begin{array}{l}\text { Audios } \\
\text { de clase }\end{array}$ \\
\hline
\end{tabular}

Curso 2018-2019

\begin{tabular}{lrrrrrrr}
\hline Mañana & 89 & 8,54 & 8,48 & 8,58 & 8,08 & 8,80 & 8,80 \\
Tarde & 33 & 8,36 & 8,76 & 9,33 & 8,48 & 8,64 & 9 \\
\hline Total & 122 & & & & & & \\
\hline Total mediana & & 8,45 & 8,62 & 8,96 & 8,28 & 8,72 & 8,90 \\
\hline
\end{tabular}




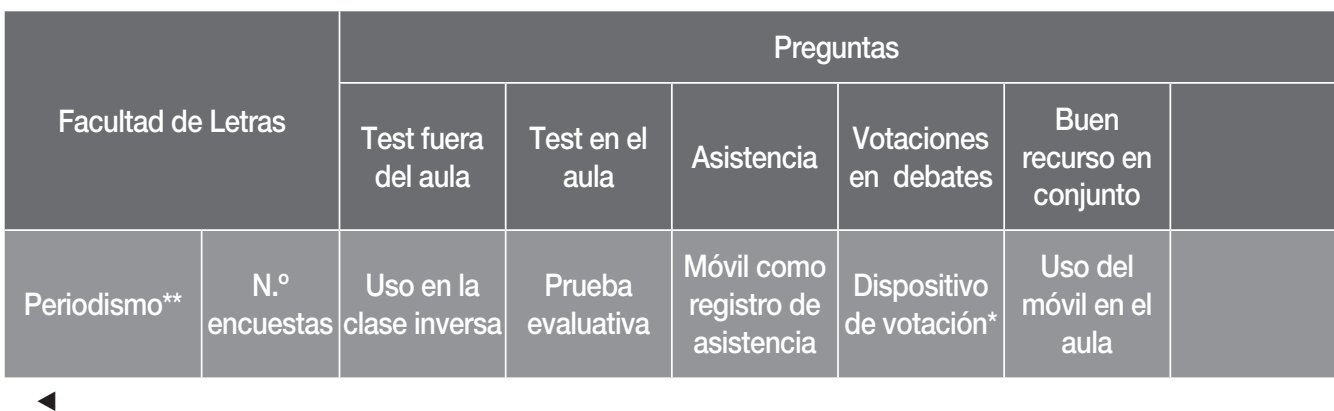

\begin{tabular}{|c|c|c|c|c|c|c|c|}
\hline \multicolumn{8}{|c|}{ Curso 2019-2020 } \\
\hline Mañana & 115 & 8,04 & 8,45 & 9,33 & 8,21 & 8,56 & \\
\hline Tarde & 96 & 7,86 & 7,95 & 9,09 & 8,49 & 8,79 & \\
\hline Total & 211 & & & & & & \\
\hline \multicolumn{2}{|l|}{ Total mediana } & 7,95 & 8,20 & 9,21 & 8,35 & 8,68 & \\
\hline Medias totales & 333 & 8,20 & 8,41 & 9,08 & 8,31 & 8,70 & 8,90 \\
\hline $\begin{array}{l}\text { * Hay que tener } \mathrm{e} \\
\text { ** Periodismo, Co }\end{array}$ & inta que & $\begin{array}{l}\text { as valor } \\
\text { sual } \mathrm{R}\end{array}$ & $\begin{array}{l}\text { on subje } \\
\text { Públicas }\end{array}$ & $\begin{array}{l}\text { I resulta } \\
\text { dad. }\end{array}$ & votacio & or la her & en concre \\
\hline
\end{tabular}

Fuente: elaboración propia a partir de las encuestas efectuadas a los estudiantes durante los cursos 2018-2019 y 2019-2020.

Si añadimos además las encuestas oficiales que la propia universidad realiza entre los estudiantes para valorar la metodología del docente, vemos que ante la pregunta « ¿La metodología de enseñanza se adecua a los objetivos de la asignatura?», los estudiantes la han valorado con una puntuación de 8,90 frente a la media de la universidad, que es de 7,35. El total de estudiantes encuestados ha sido de 216.
Ante la pregunta «iLa metodología de enseñanza se adecua a los objetivos de la asignatura?», los estudiantes la han valorado con una puntuación de 8,90 frente a la media de la universidad, que es de 7,35. El total de encuestados ha sido de 216

\subsection{Impacto en la docencia}

Con la implementación de esta app, el profesorado puede cambiar la forma tradicional de impartir las clases magistrales y las prácticas a través de la incorporación de nuevas estrategias metodológicas y novedades tecnológicas con el uso de los dispositivos móviles. Y, sobre todo, puede cambiar el rol de los dispositivos móviles con el fin de hacerlos cómplices de la docencia en lugar de un elemento de distracción y falta de atención. Los impactos constatados que hemos logrado con el uso de la app se pueden ver en el cuadro 12. 


\section{Cuadro 12. Impacto de la app en la docencia}

\section{PowerPoint con funciones interactivas}

Posibilidad de feedback constante con los estudiantes durante la clase para comprobar el grado de asimilación de contenidos.

Permite reforzar contenidos no asimilados por una mayoría de la clase.

Avance progresivo en la comprensión de la materia.

Aumenta la participación y aporta dinamismo.

Ayuda a mantener la atención permanentemente del estudiante a través de la ludificación, creando competitividad estimuladora.

En suma, mejora el rendimiento de las exposiciones magistrales.

\section{Pruebas evaluativas}

Facilidad en la realización de pruebas evaluativas tipo test, etc., de forma sencilla.

Utilización en cualquier aula. No necesita de equipos informáticos para cada estudiante.

Corrección online, generando archivos de resultados automáticos inmediatos.

Apto para clases masificadas.

Elimina los lectores ópticos de corrección de test y su coste.

Proporciona una base de datos de pruebas que permite tutorías personalizadas.

Genera ficheros Excel adaptables a Moodle, etc.

\section{Pruebas evaluativas virtuales fuera del aula}

Facilita el trabajo autónomo del estudiante fuera del aula y su calificación (por ejemplo, impacto de la COVID-19).

Permite la aplicación de la clase inversa (flipped classroom).

El estudiante adquiere conocimientos de la materia previos a la explicación.

El docente constata el grado de conocimientos y la participación en la actividad.

Estimula el debate (el estudiante tiene conocimiento previo de la materia).

\section{Asistencia a clase, cursillos y reuniones}

Registro optativo de asistencia más efectivo y eficaz que la firma sobre papel.

Propicia la asistencia a clase.

Registra el porcentaje de asistencia diaria a clase. Permite modificar pautas.

Útil también para registrar la asistencia a cursillos, reuniones y eventos.

Proporciona una base de datos total de asistencia a clase por cuatrimestre.

\section{Votaciones}

Incrementa la participación en decisiones de la clase.

Incrementa la motivación en las actividades de grupo que requieren tomar una decisión conjunta de la clase. 
Agiliza la decisión.

Pone a prueba la responsabilidad del alumnado y permite incidir en una educación en valores.

Adaptable a los diversos usos que el profesorado le puede dar.

Fuente: elaboración propia.

Asimismo, la mejora de la evaluación permite planificar tutorías personales y simulaciones de nota con los estudiantes cuya nota media esté por debajo de la media de la clase y así reconducir sus esfuerzos y estudio para obtener buenos resultados a final del curso. Muestra de ello son las siguientes tasas de éxito y rendimiento (véase cuadro 13).

\section{Cuadro 13. Tasas de éxito y de rendimiento globales}

\begin{tabular}{|c|c|c|c|c|c|}
\hline \multicolumn{3}{|c|}{ Tasa de éxito de Derecho } & \multicolumn{3}{|c|}{ Tasa de rendimiento de Derecho } \\
\hline Aprobados & 73 & $78,50 \%$ & Aprobados & 73 & $70,20 \%$ \\
\hline Presentados & 93 & & Matriculados & 104 & \\
\hline \multicolumn{3}{|c|}{ Tasa de éxito de Comunicación } & \multicolumn{3}{|c|}{ Tasa de rendimiento de Comunicación } \\
\hline Aprobados & 67 & $93,10 \%$ & Aprobados & 67 & $88,20 \%$ \\
\hline Presentados & 72 & & Matriculados & 76 & \\
\hline
\end{tabular}

Nota: los estudios de Comunicación constan de los grados de Periodismo, Comunicación Audiovisual y Publicidad y Relaciones Públicas.

Fuente: elaboración propia en función de la calificación de actas de los cursos 2018-2019 y 2019-2020.

Con todos estos datos podemos constatar los resultados obtenidos con credibilidad científica, lo que nos permite afirmar la bondad del método docente expuesto y el grado de efectividad y motivación que despierta en el alumnado ${ }^{7}$.

\subsection{Visibilidad del método}

Una app de estas características es pionera en las universidades. Su implantación puede convertirse en un componente de calidad en las TIC que da prestigio y sitúa a la facultad/

7 Véanse otros resultados del uso de los dispositivos móviles en el aula en Narbón-Perpiñá y Peiró-Palomino (2018). 
universidad como punto de referencia en cuanto a la adaptación de los dispositivos móviles a la docencia, lo que potencia la visibilidad de este método ${ }^{8}$.

Por otra parte, este uso de los dispositivos móviles se ha aplicado sobre la base de las metodologías que hemos venido impartiendo en cursos anteriores, en las que los dispositivos móviles y las TIC también tenían un componente docente en el aula, lo que se ha plasmado en varias comunicaciones y ponencias en congresos y jornadas, con sus correspondientes publicaciones. La experiencia de estos años nos abre nuevas vías de visibilidad, funciones y aplicaciones del uso de los móviles en el aula en las que se está trabajando.

\section{Conclusiones}

Hemos podido ver y comprobar la buena predisposición que tienen los estudiantes para el uso de los dispositivos móviles en las actividades de clase. Es del todo sabido que los móviles han venido para quedarse en las aulas. Para el alumnado se ha convertido en un dispositivo amigable que lo conecta al mundo social y, a veces, de forma exagerada, ya que su uso se antepone a la familia, en el aula, entre sus mismas amistades, por la calle, etc., es decir, el móvil tiene prioridad en sus vidas, estén donde estén. Es evidente que el docente no podrá vencer esta nueva tecnología digital y, como sabemos, si no se puede vencer, hay que unirse con ingenio a ella para convertirla en un nuevo y potente recurso educativo que acabe motivando al estudiante y propicie un mayor interés por la materia como consecuencia de la novedad que supone fomentar lo que hasta ahora estaba prohibido: el móvil en clase.

Al mismo tiempo, la utilización de los dispositivos móviles como un nuevo recurso educativo abre las puertas a la incorporación de nuevas metodologías en la docencia tradicional, dado que permite innovar con imaginación nuevas formas de plantear las clases tradicionales, a la vez que se convierte en una buena herramienta para potenciar el trabajo autónomo del estudiante fuera del aula y la evaluación no presencial (por ejemplo, impacto de la COVID-19). En definitiva, su límite está en la imaginación del profesorado.

Hemos podido analizar y comprobar algunas de las principales apps docentes que existen en el mercado y hemos visto que son muy buenas para aquello que se han creado, pero tienen debilidades manifiestas (son plataformas que escapan al control de nuestros datos y accesibilidad), por eso hemos optado por la creación de una app a la medida de nuestras necesidades, en función de la experiencia constatada, que permita un control total de los datos y accesibilidad, que sea sencilla e intuitiva de manejo y que sea transversal, para que sirva en otras facultades o universidades con garantías de éxito.

8 Una de las clases impartidas con el uso de los móviles, en la que se participaba en una liga de debates, fue retransmitida en directo por Radio 96.7 FM el día 5 de diciembre de 2018. 
Para implantar esta nueva app, hemos creado una beca-proyecto de carácter social para ayudar a una mayor integración de las mujeres de las minorías étnicas más desfavorecidas en el ámbito universitario. Así, se ha incorporado a una persona que reúne estas características en las tareas de diseño de la app. Hemos buscado financiación sufragada por un micromecenazgo. Para su desarrollo, hemos contado con la colaboración de la ETSI.

Esta experiencia nos ha abierto un horizonte a nuevos proyectos si conseguimos financiación, como el desarrollo de nuevas adaptaciones para congresos y jornadas, así como una agenda del estudiante en la que pueda planificar su aprendizaje y se convierta en una plataforma de contacto e información de los eventos del campus.

Nuestra pretensión es que este proyecto sirva de pauta para que otras universidades puedan diseñar y crear su propia app y que permita dar una respuesta al reto que las universidades tienen planteado con el uso de los móviles en el aula, convirtiéndolos, con imaginación, en una potente herramienta como recurso educativo.

\section{Referencias bibliográficas}

Bain, K. (2007). Lo que hacen los mejores profesores universitarios, Universitat de Valencia.

Berenguer-Albaladejo, C. (2016). Acerca de la utilidad del aula invertida o flipped classroom. Universidad de Alicante; Instituto de Ciencias de la Educación.

Cabero Almenara, J. y Barroso Osuna, J. (2015). Nuevos retos en tecnología educativa. Síntesis.

García-Barrera, A. (2013). El aula inversa: cambiando la respuesta a las necesidades de los estudiantes actuales. Revista de la Asociación de Inspectores de Educación de España, 19, 1-8.

Hernando Parra, N. y Arenas-Dolz, F. (2015). Revolución tecnológica y democracia del conocimiento: por una universidad innovadora. Amazon.

Narbón-Perpiñá, I. y Peiró-Palomino, J. (2018). La plataforma Socrative como herramienta de aprendizaje: una aplicación a la asignatura Métodos Cuantitativos. e-pública. Revista Electrónica sobre la Enseñanza de la Economía Pública, 42, 41-50.
Nasarre Aznar, S. (Septiembre 2013-Marzo 2014). Aumentando la interacción en el aula ordinaria mediante el iPad y demás dispositivos de m-learning. Revista de Educación y Derecho, 9, 1-28.

Reyero Sáez, M. (2019). La educación constructiva en la era digital. Tecnología, Ciencia y Educación, 12, 111-127.

Ruiz, R., Martínez, R. y Valladares, L. (2012). Innovación en la educación superior: hacia las sociedades del conocimiento. Fondo de Cultura Económica.

Santiago Campión, R., Trabaldo, S., Kamijo, M. y Fernández, A. (2015). Mobile learning: nuevas realidades en el aula. Digital-Text; Editorial Océano.

Vázquez-Cano, E. y Sevillano, M. ${ }^{a}$ L. (2015). Dispositivos digitales móviles en educación: el aprendizaje ubicuo. Narcea.

Yániz Álvarez, C. (2006). Planificar la enseñanza universitaria para el desarrollo de competencias. Educatio Siglo XXI, 24, 17-34. 